دور المحاسبة الإدارية الإستراتيجية في تدعيم القدرة التنافسية

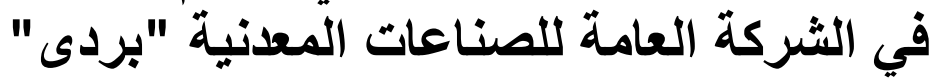

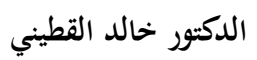 \\ أستاذ -قسم المحاسبة \\ كلية الاقتصاد -جامعة حلب
}

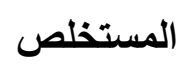

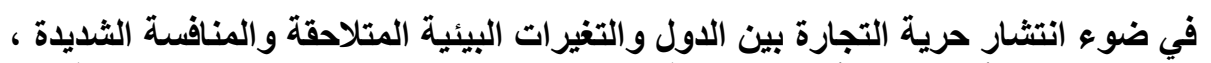

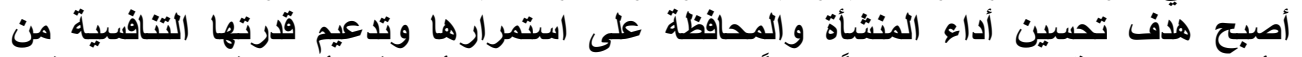

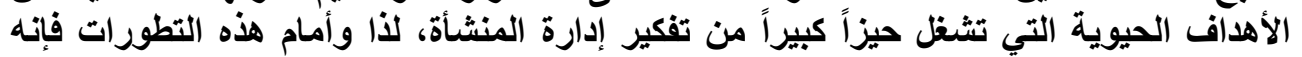

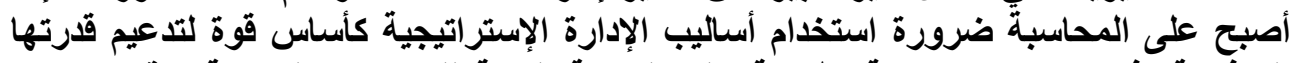

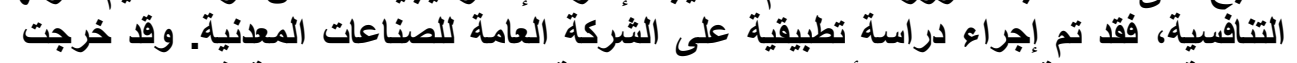

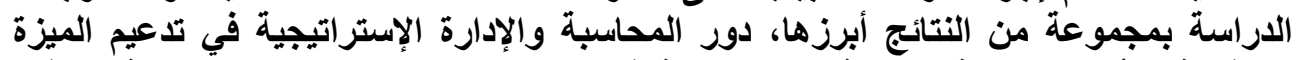

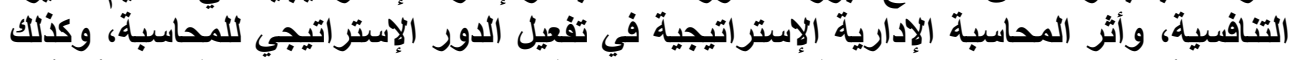

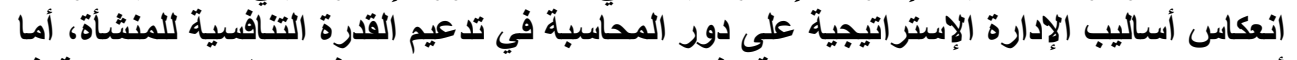

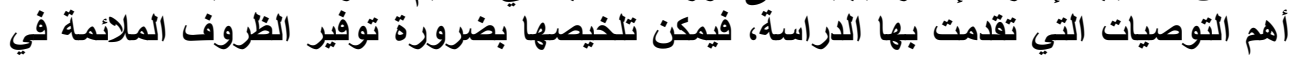

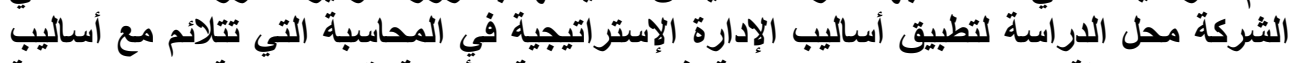

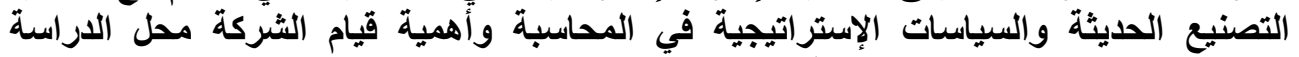
بإخضاع العاملين إلى دورات تدريبية لنطوير مهاراتهم وخبراتهم.

الكلمات المفتاحية: 


\title{
The Role of Strategic Accounting Management in Supporting the Competative Advantage in the State Company of Mine Industries (Burda)
}

\author{
Khalid Al-Kutainy (PhD) \\ Professor \\ Department of Accountancy \\ University of Aleppo
}

\begin{abstract}
The proliferation of free trade between states and environmental changes, successive, the goal of improving the performance of the enterprise and maintaining and strengthening its competitiveness in light of the intense competition of the vital goals that takes up so much of the thinking management of the enterprise, so the face of these developments, it became the accounting need to use the methods of strategic management force as a basis to strengthen their competitiveness, a study has been applied to the Company for Metallurgical Industries. The survey has a range of results, notably, the role of accounting and strategic management in strengthening the competitive advantage, and the impact of management accounting strategy in the activation of the strategic role of accounting, as well as a reflection of the methods of strategic management on the role of accounting in strengthening the competitiveness of the facility, but the most important recommendations made by the study, it can be summarized the need to provide the appropriate conditions in the company under consideration for the application of methods of strategic management in accounting methods that fit with the modern manufacturing and strategic policies in accounting and the importance of the company under consideration by subjecting employees to training courses to develop their skills and experience.
\end{abstract}

\section{Keywords:}

Strategic Accounting, Competitiveness, Strategic Planning, Strategic Knowledge.

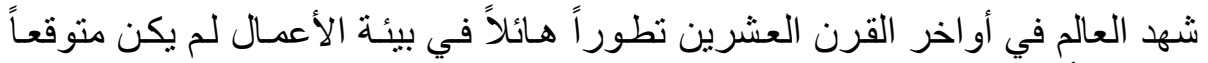

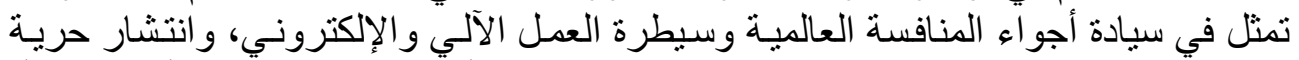

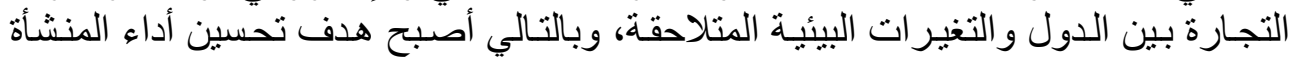

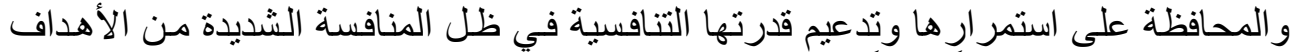

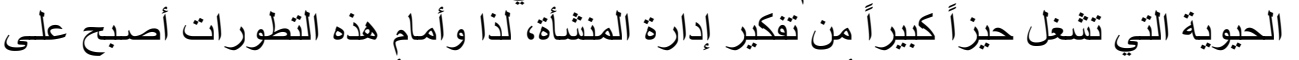

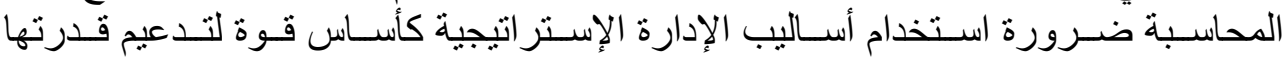
التنافسية.

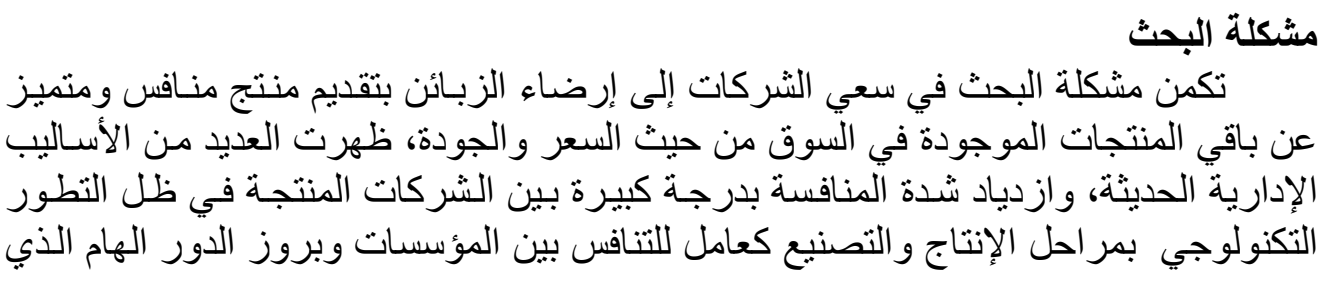




\section{[191 القطيني[1]}

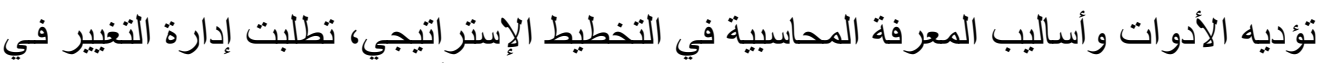
الفكر المحاسبي والمالي حتمية تحسين ورفع كفاءة وفاعلية الأسـاليب المحاسبية والية والمحاسبين،

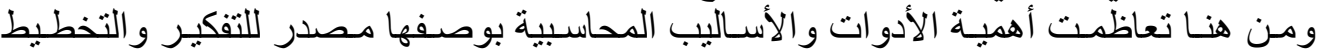

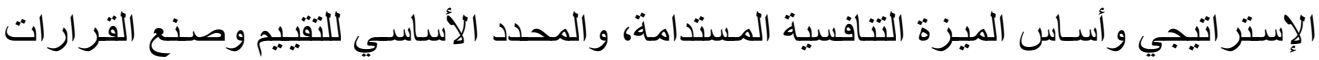

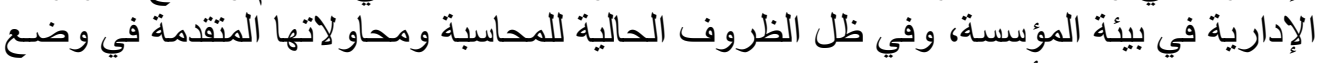

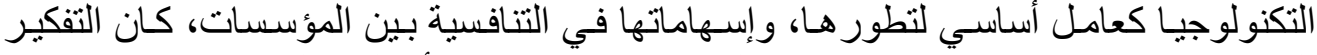

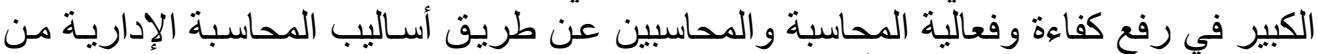

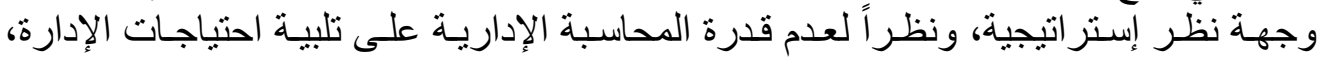

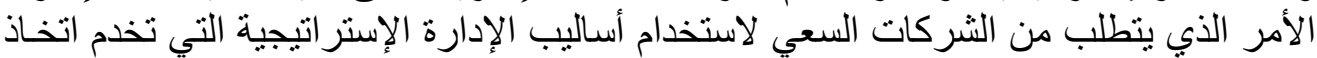

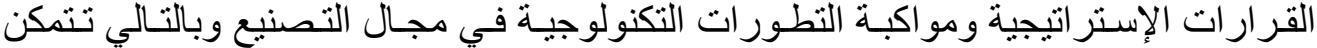
الثركات من تدعيم قدرتها التنافسية.

يمكن إظهار أهمية البحث في ناحيتين:

أهمية البحث

الأهمية العلمية للبحث

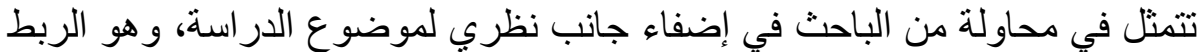

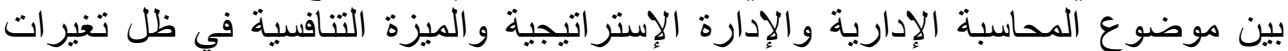

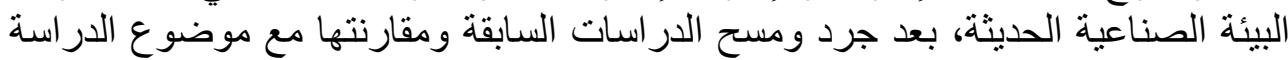
الحالية وتحديد مجالات تميز الدراسة عنها.

الأهميـة العمليـة للبحث

تتمثل في تناول وتوضيح وبيان أهمية التوجه الإستر اتيجي في تعزيز الميزة التنافسية

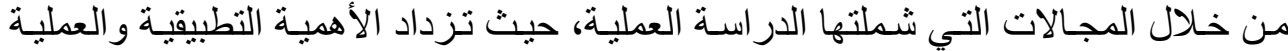

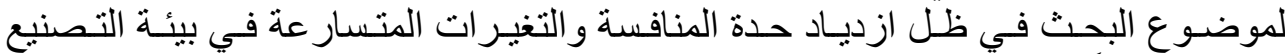

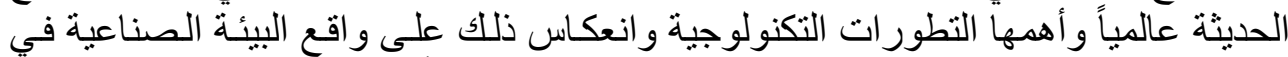
سوريا وبشكل خاص في مدينة حلب، الثركات التورئ العامة أنموذجاً.

$$
\text { أهداف البحث أهداف البحث في جملة من النقاط: }
$$

ا. بيان دور الإدارة الإستر اتيجية في تفعيل الدور الإستر التيجي للمحاسبة.

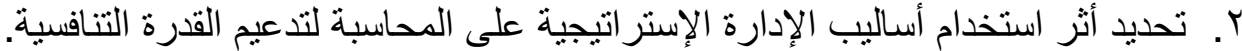

r. ب بيان دور أساليب المحاسبة الإدارية الإستر اتيجية في تعزيز المية الميزة التنافسية.

يمكن تحديد الفرضيات التي سيتتاو لها الباحث بما يلي:

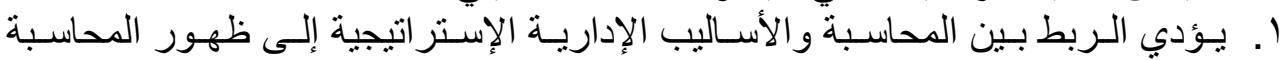

الإدارية الإستر اتيجية. 
Y. بـؤدي اسـتخدام المحاسـبة الإداريسة لأسـاليب الإدارة الإسـتر اتيجية إلـى تـدعيم القـدرة التنافسية للمنشأة وزيادة الحصة السوقية لها.

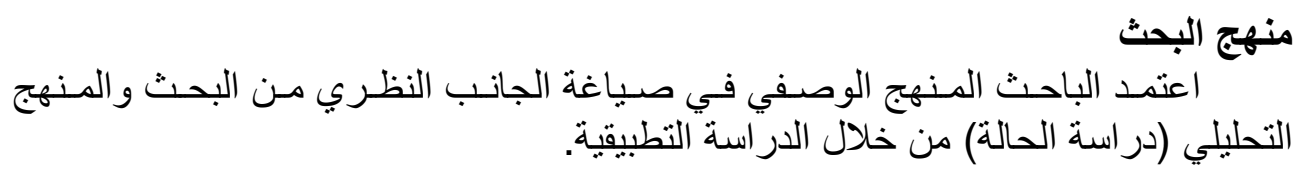

أولاً- دور الإدارة الإستراتيجية في تفعيل الدور الإستراتيجي للمحاسبة

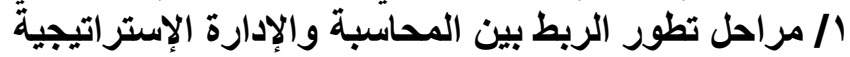

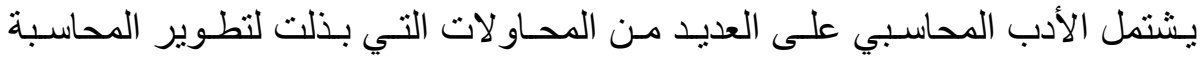

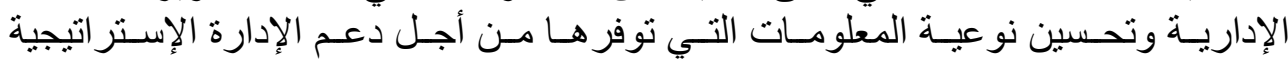

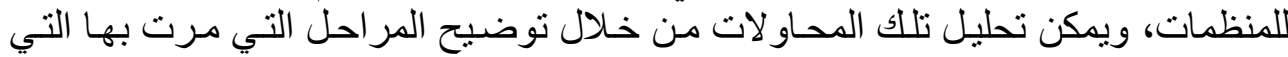
تتمثل في المر احل الثلاثة التالية:

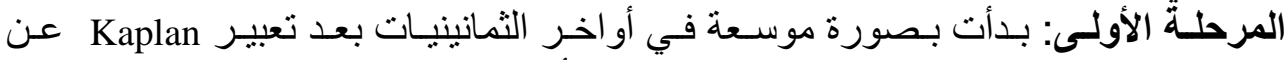

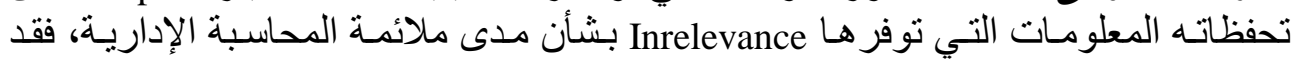
جادل بعدم ملائمة المحاسبة الإدارية كي تعتمد عليها الإدارة لتحقيق ميزة تنافية التهية مستدامة،

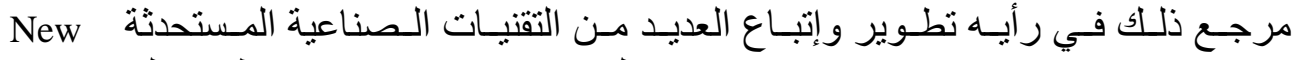
Manufacturing Technologies

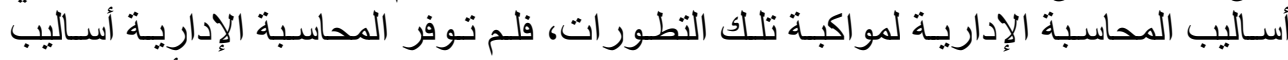

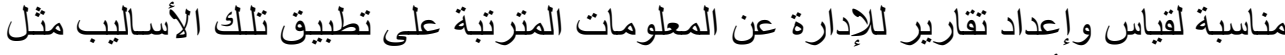

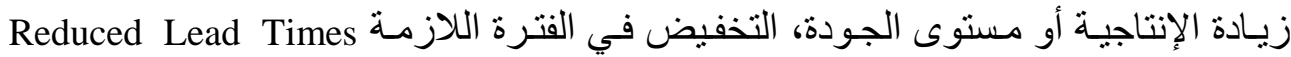

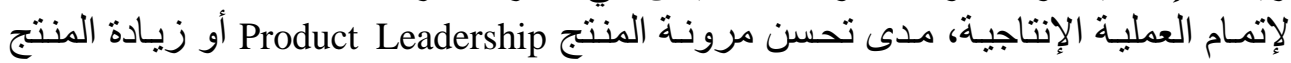
Improved Product Flexibility للمنظمات [Kaplan, 1983, 1984,1988].

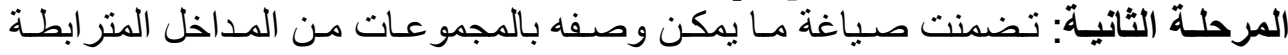

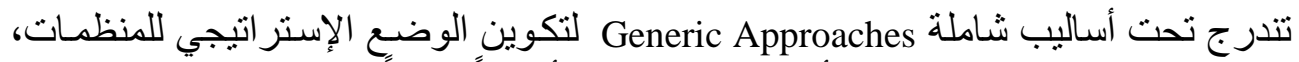

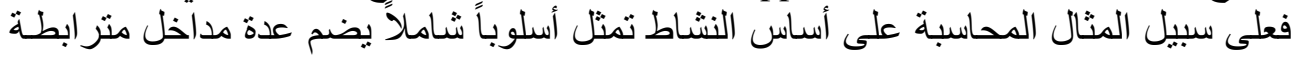

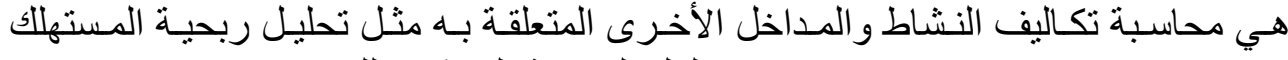

Direct Product Profitability Analysis Customer

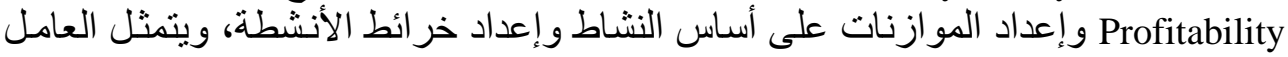

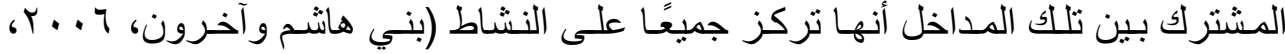
( $(101$

ويطلق Roslender على المجموعة الثانية من المداخل المترابطة مصطلح "المحاسبة

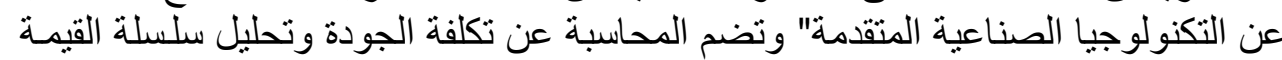

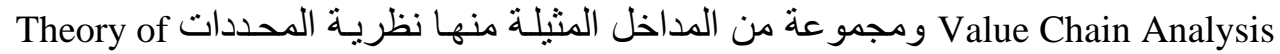
Constraints للأداء Roslender,1995,23) Continuous Performance Improvement). 


\section{القطيني[19 19 [-}

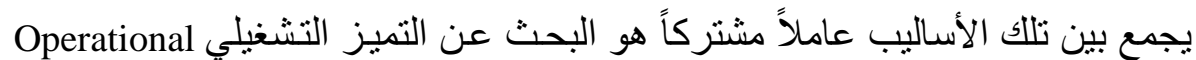
Excellence موضو عات ومفاهيم المحاسبة الإدارية و إدارة الإنتاج و إدارة العمليات

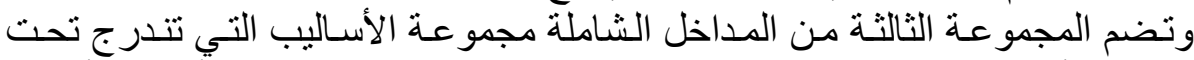

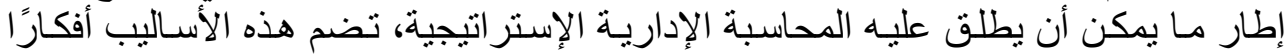

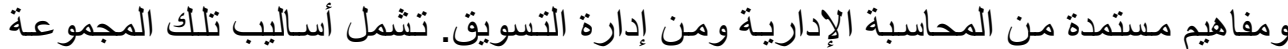

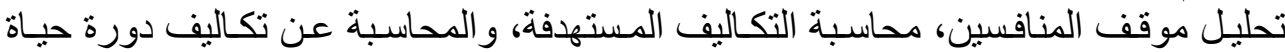

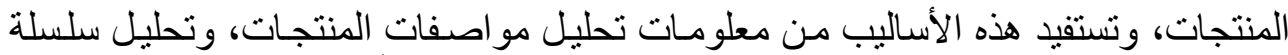

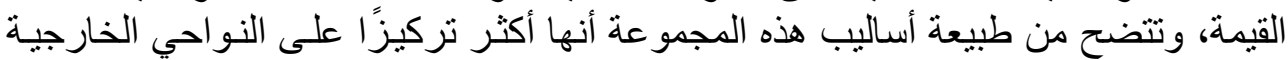

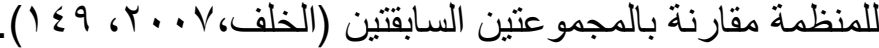
المرحلة الثالثة: يرى Roslender and Hart أن أهم مـا يميزهـا هو هو صياغة مجمو عـة من

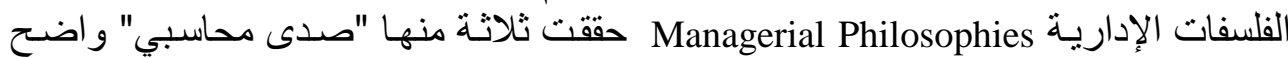
هي الإدارة على أساس النشاط، و إدارة التكلفة الإستر اتيجية، وإدارة التكلفة المستهدفة. يوجد

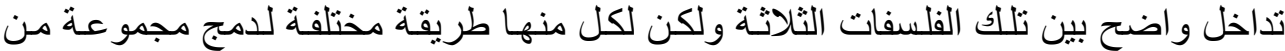

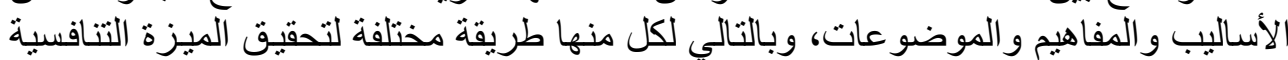
المستدامة للمنظمات (Roslender and Hart, 2002).

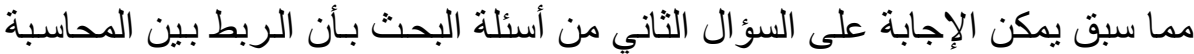

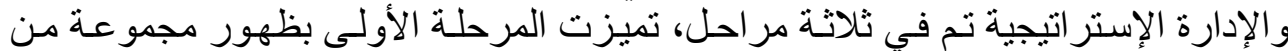

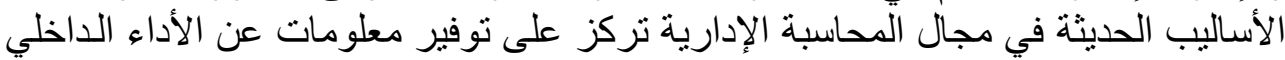

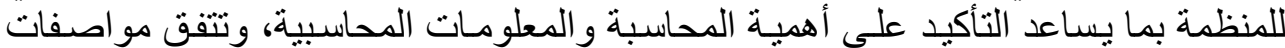
تللك المرحلة مع تفسير المدخل الانتقادي لنشأة المحاسبة الإستر اتيجية.

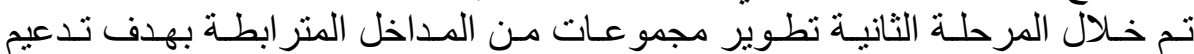

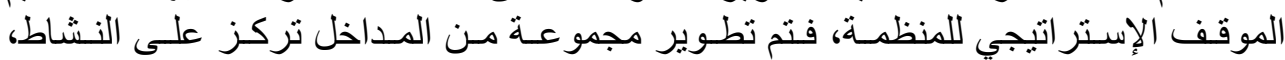

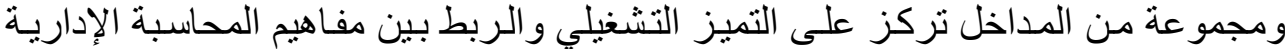

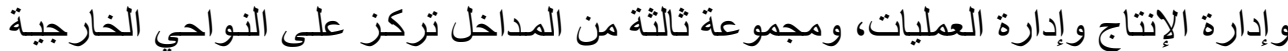

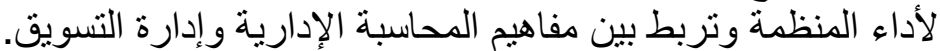

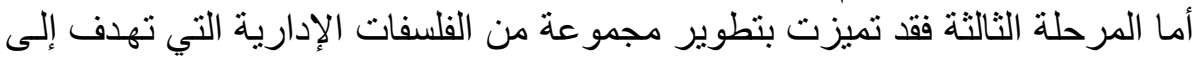

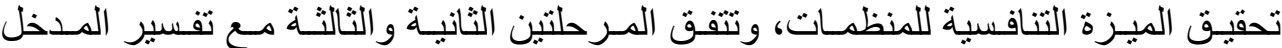

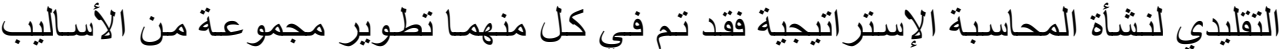

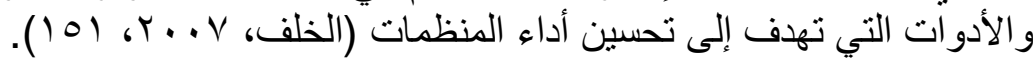

r/ اتجاهات دمج المحاسبة والإدارة الإستراتيجية

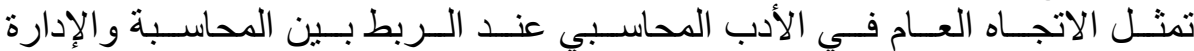

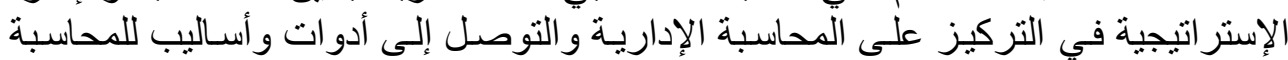

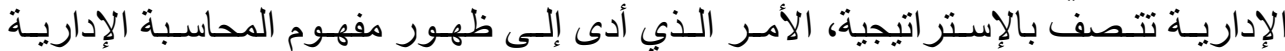

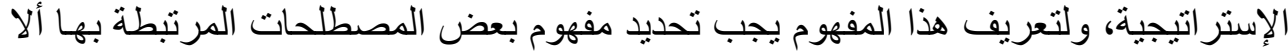
وهي الإستر اتيجية والإدارة الإستر الإنيجة الإنيجة

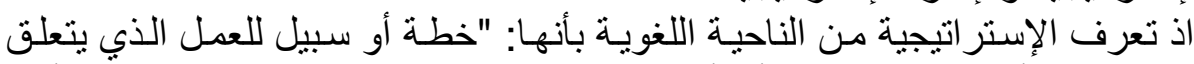

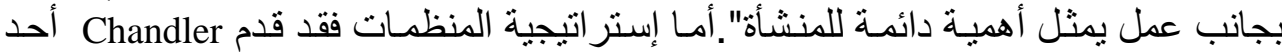


أقدم وأعم تعريفاتها حيث وصف الإستر اتجية بأنها "تحديد الأهداف الأساسية طويلـة الأجل

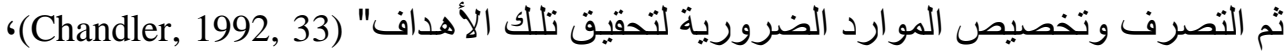

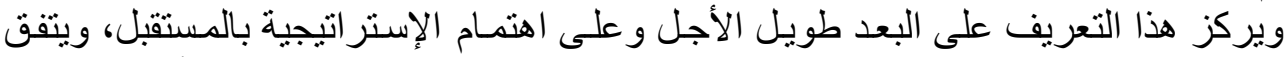
هذا التعريف مـع نظرة

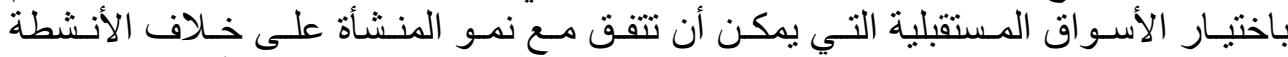

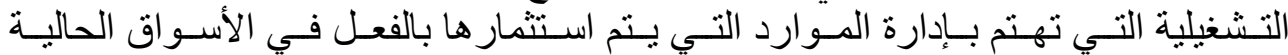

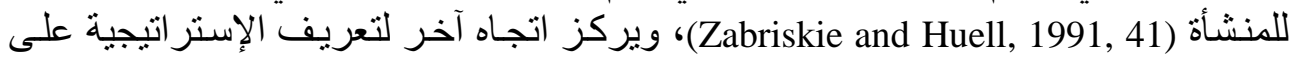

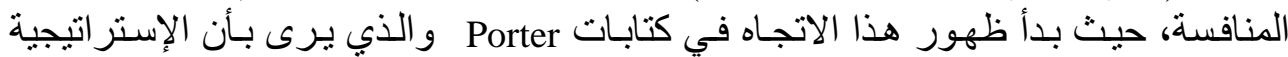

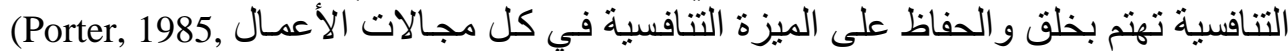

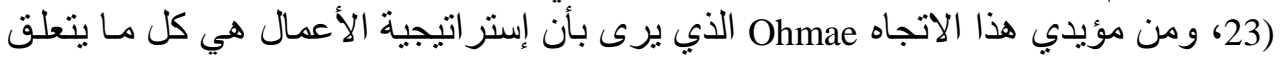

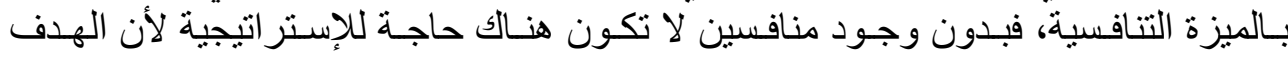

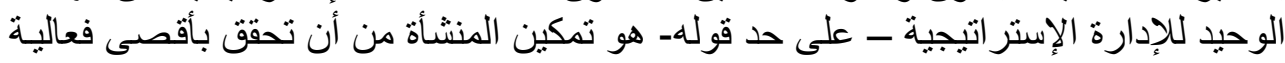
ميزة مستمرة عن منافسيها. كما أنه لا يوجد تعريف متفق عليه الإدارة الإستر اتيجية حيث تعرف بأن بأنها "التركيز

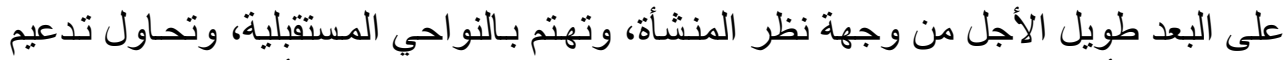

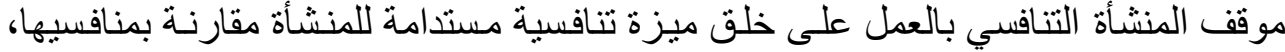

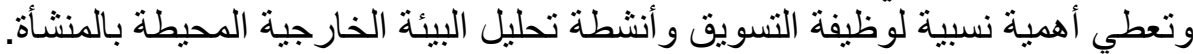

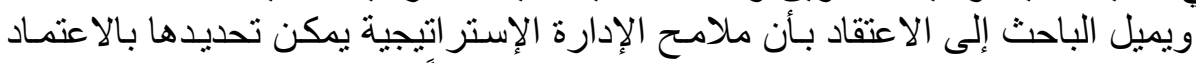

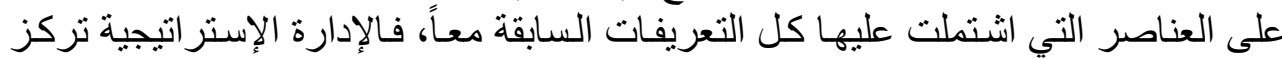

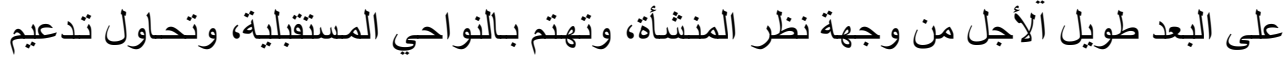

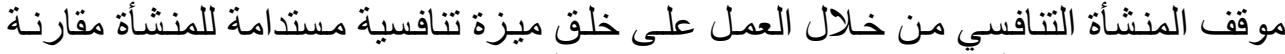

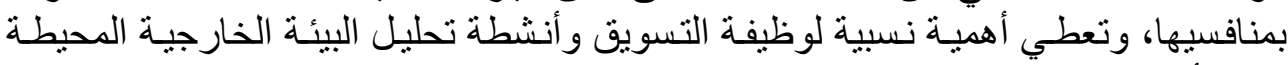

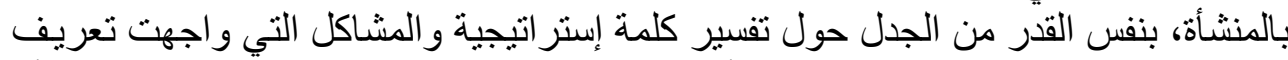

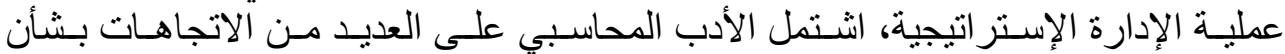

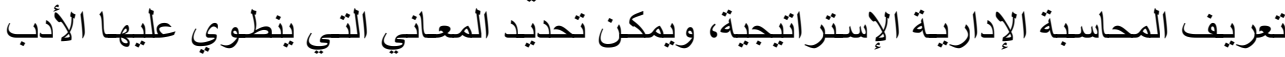

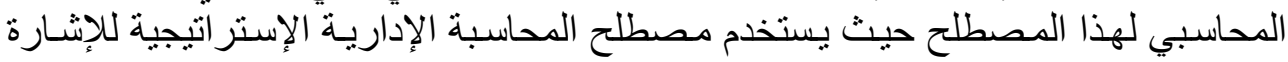

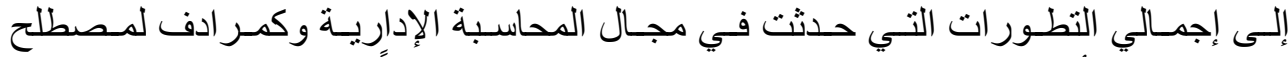

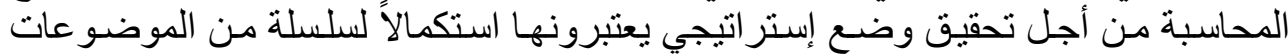

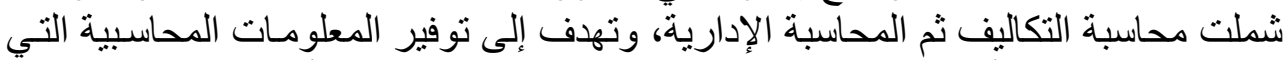

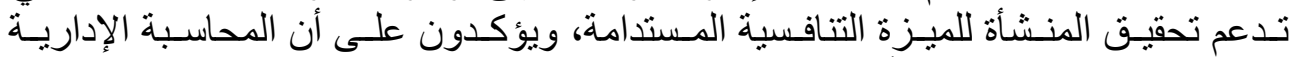

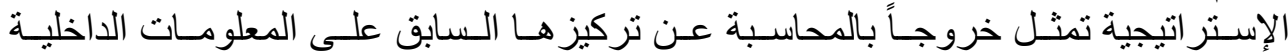

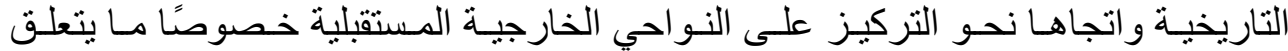
بالمنافسين و العملاء و البيئة الخارجية ندية

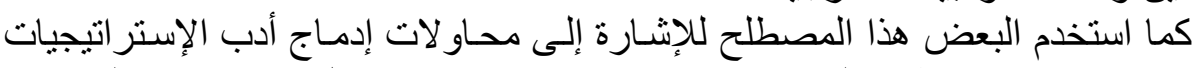

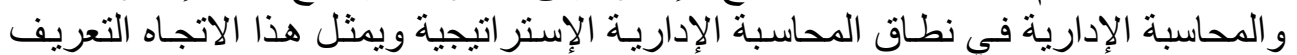

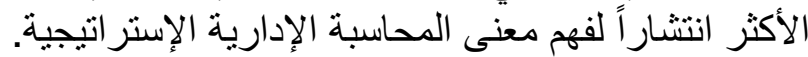

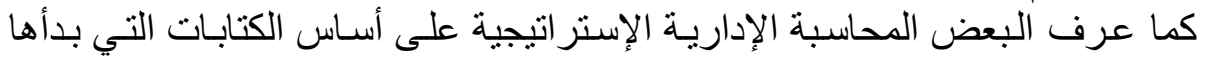

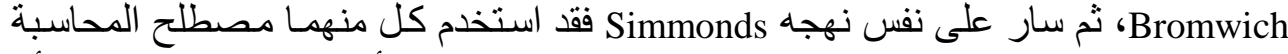
الإدارية الإستراتيجية بكثرة، ولكنهما استخدماه بمفهوم يقوم على أنها نوع من المحاسبة أو أو 


\section{[190] القطيني}

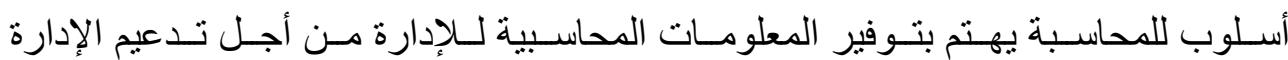
الإستر اتيجية، ويعتبر Simmond هو أول من أطلق مصطلح المحاسبة الإدارية الإستر اتيجية

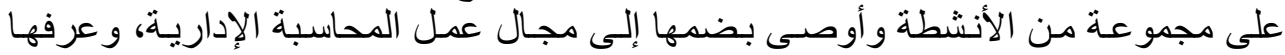

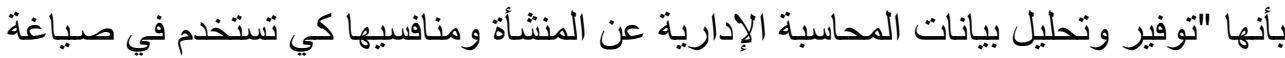
ومراقبة إستراتيجية الأعمال"، ونادى Simmonds بأن المحاسبين الإداريين هم الأقَّر على الإنى

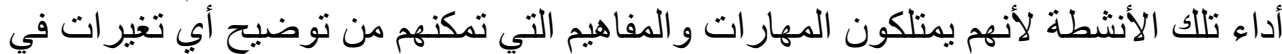

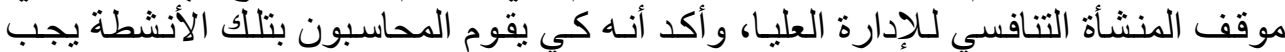

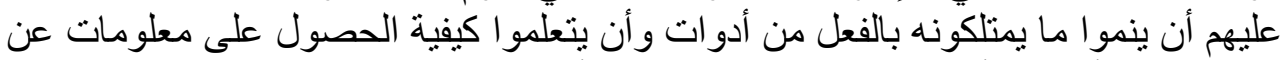

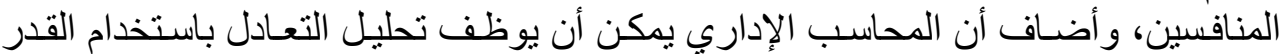

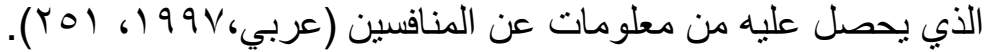

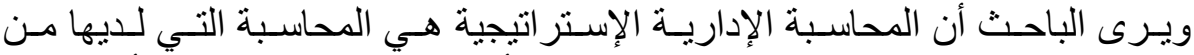

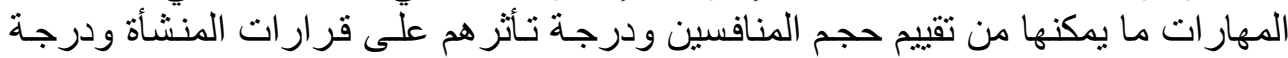

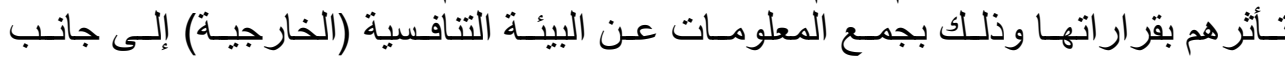

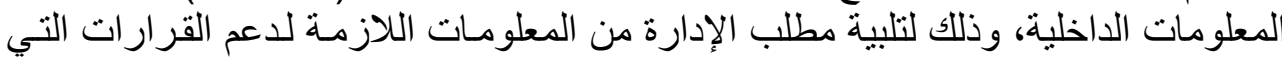

ستأخذها.

\section{ب/ مرتكزات المحاسبة الإدارية الإستراتيجية الإنية}

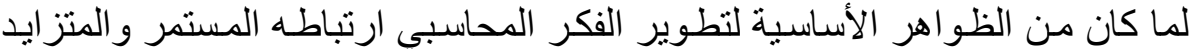

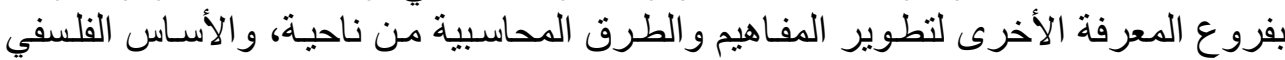

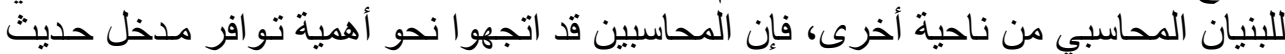

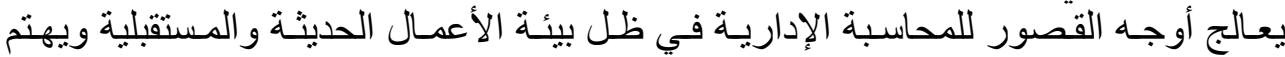

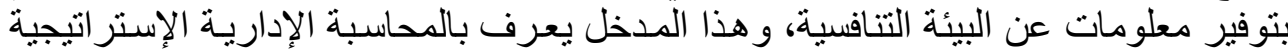

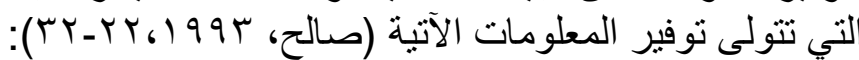

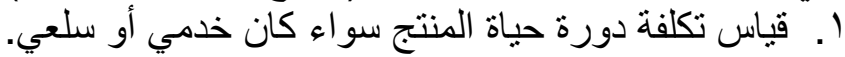
r. توفير المقاييس غير المالية اللازمـة لإدارة الجودة الشاملة، مثنل قياس عدد الشكاوى للزبائن عدد الوحدات الرديئة المعيبة.

1- قياس تكاليف جودة الخدمة والتي تتحقق من خلال توفير المعلومات لإدارة التكلفة التي

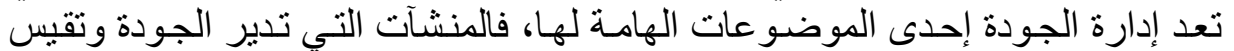
تكلفتها تتمتع بميزة تنافسية.

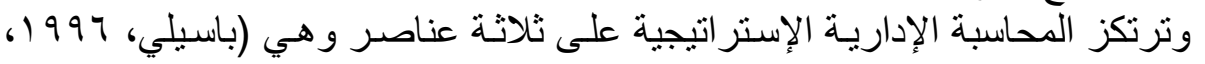

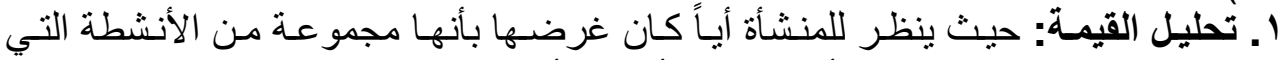

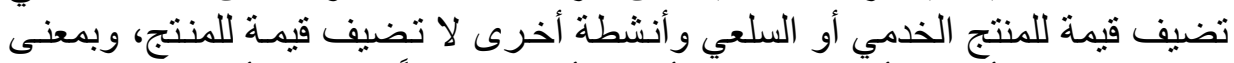

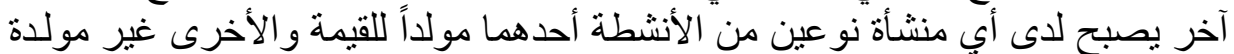

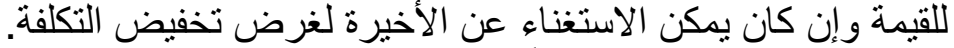

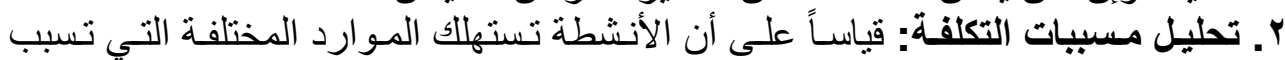

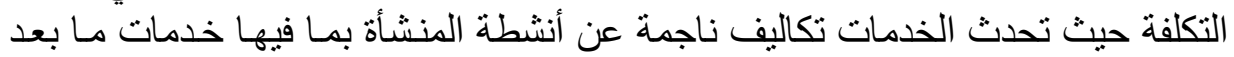

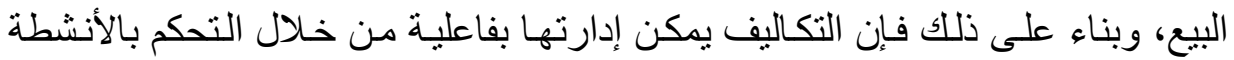




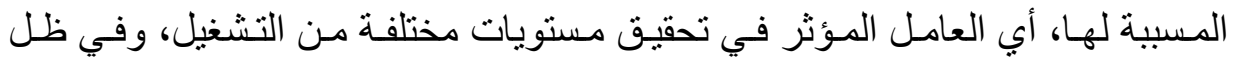

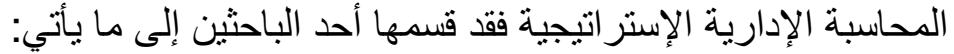

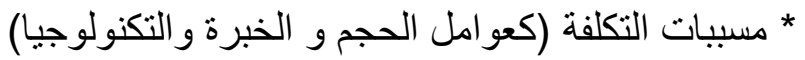

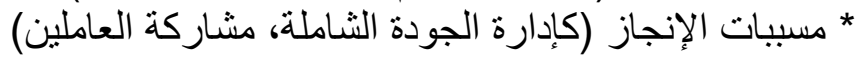

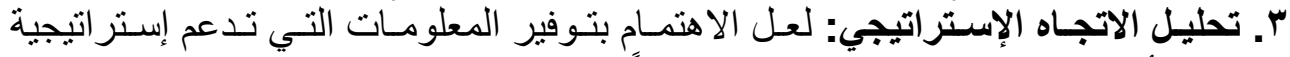

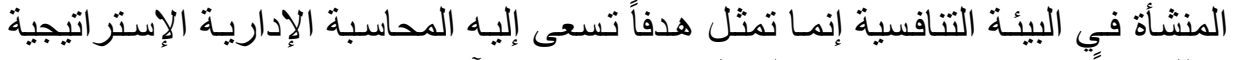
وذللك تبعاً لاستخدامها في حسم البدائل الإستر اتيجية الآنية التية:

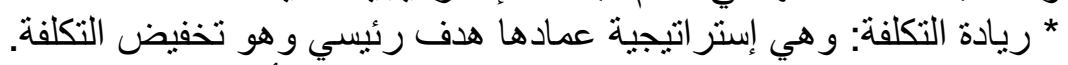
* تمييز المنتجات: و تستخدم تللك الإستر اتيجية في تقديم أفضل المناف المنتجات.

ثانياً انعكاس أساليب الإدارة الإستراتيجية على المحاسبة

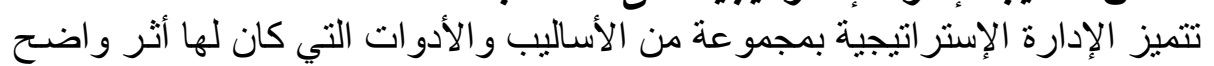

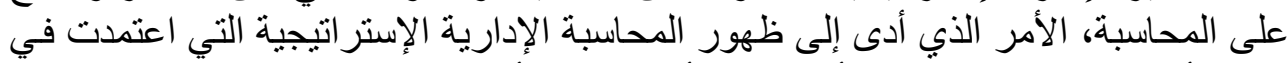
تحقيق أهدافها على العديد من الأساليب والألى الأدوات ومن أهمها:

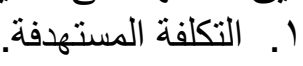

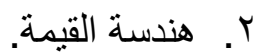
r. ع. التحسين المستمر للجودة.

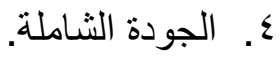
وفيما شرح موجز لكل من هذه الأن الساليب:

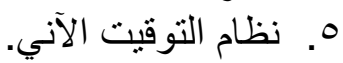

1ـ التكلفة المستهدفة

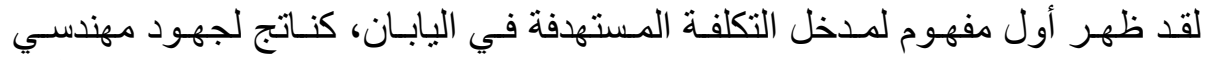

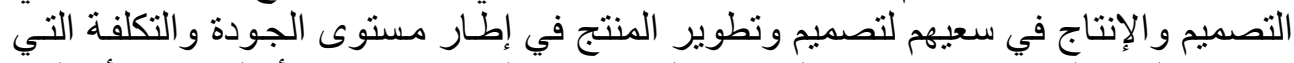

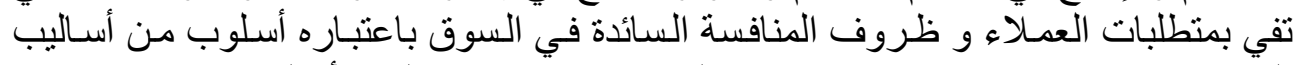

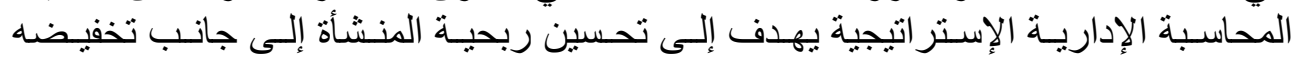

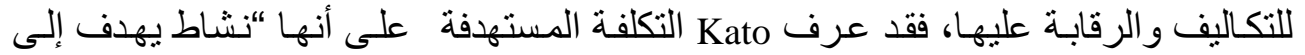

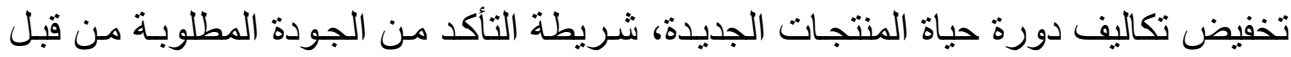

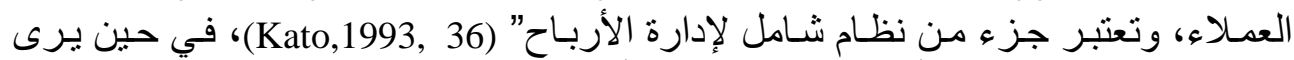
Castellano and Young

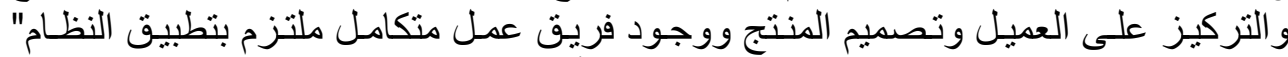
(Castellano and Young ,2003, 149)

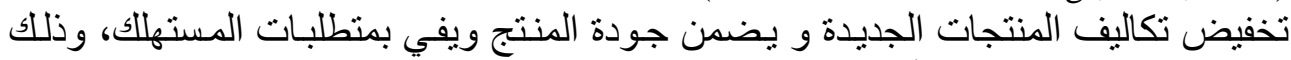

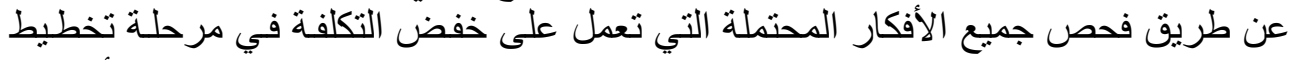

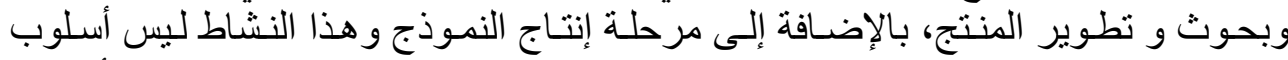

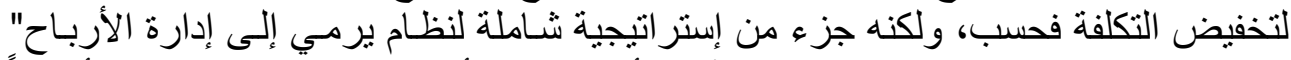

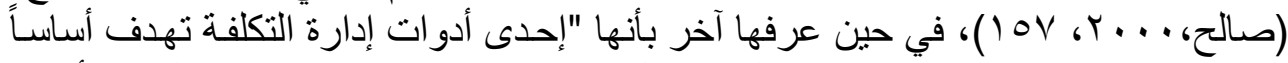

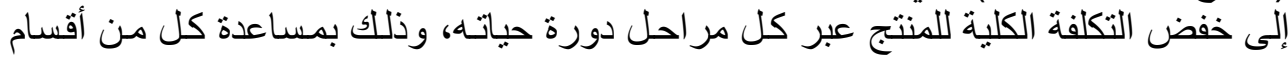

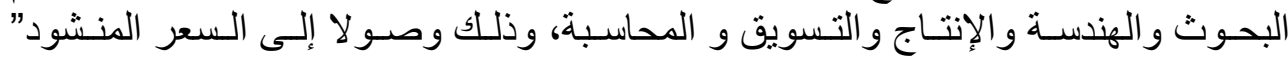




\section{[19V] القطين}

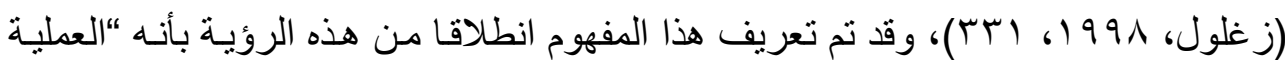

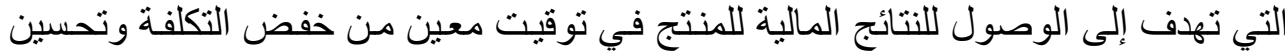

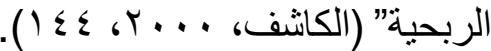

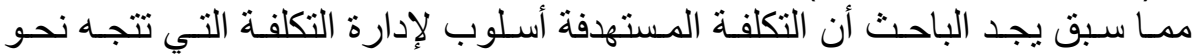

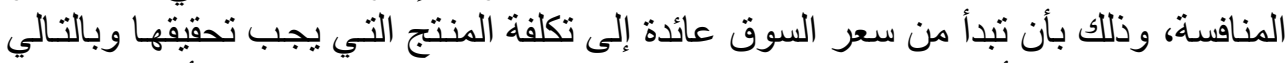
تحسين ربحية المنشأة بالوصول الربح المستتهدف وتدعيم القدرة التنافسية للمنشأة.

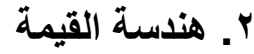

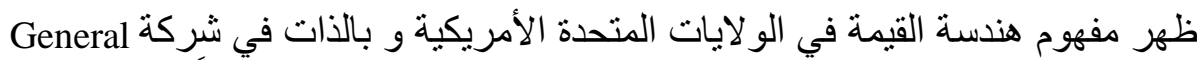
Electric

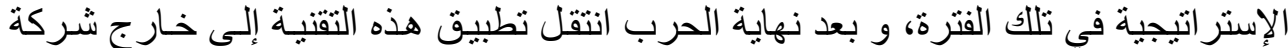

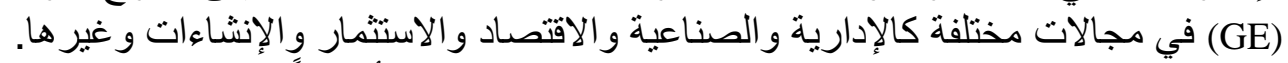

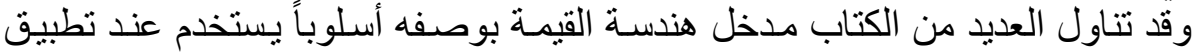

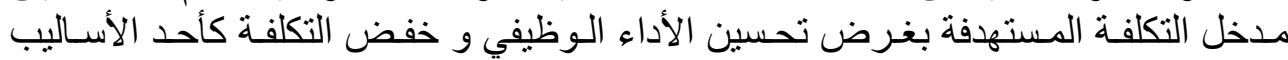

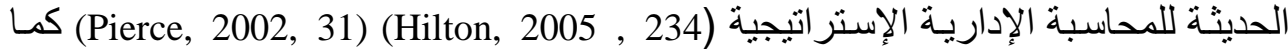
American يوجد تعاريف متعددة لهندسة القيمة إذ عرفتها الجمعية الأمريكية لمهندسي القيمة ين تطبيق منهجي لإجر اءات محددة يتن Association of Value Engineers International

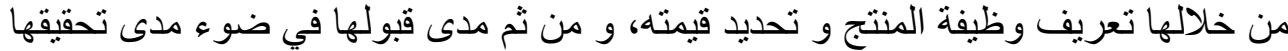

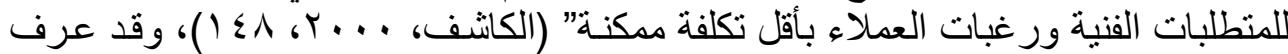

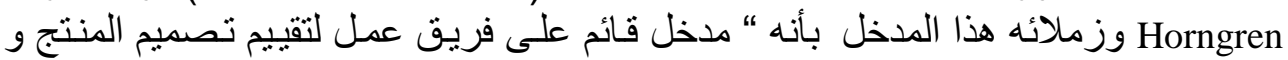

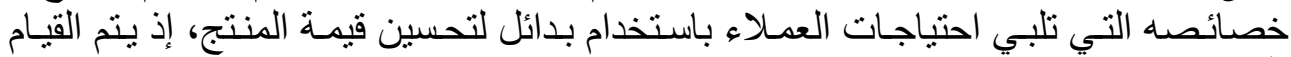
بأنشطة القيمة بالاتصال المتبادل بين مديري التسويق ومصمصي الإنتاج ومشرفي الإنتاج

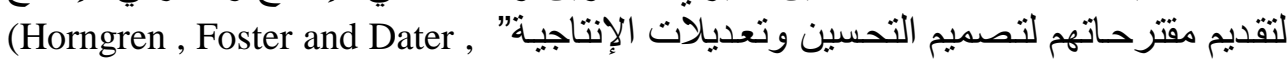
.1997,437)

في حين يرى Sakurai أن هندسة القيمة تعرف بأنها "نشاط خاص بتصميم المنتج في الإحي مختلف مر احلـه بهدف تخفيض التكلفة مـع المحافظـة على الاحتياجـات المطلوبـة مـن قبـل فئل المستهلكين (Sakurai,1989, 44).

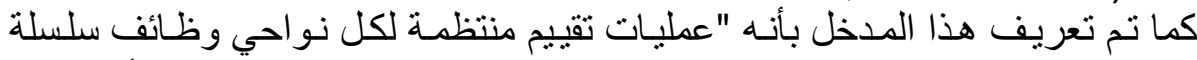

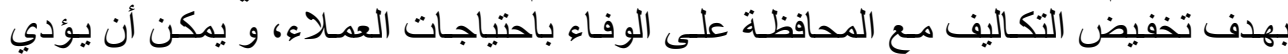

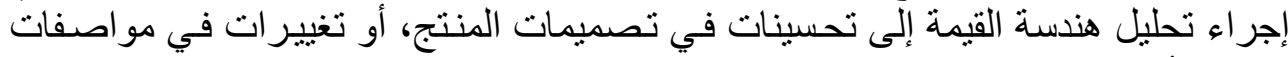

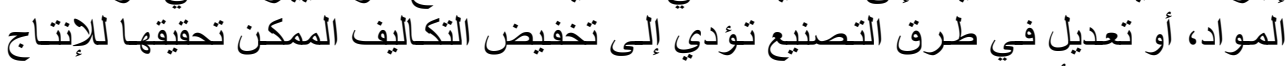

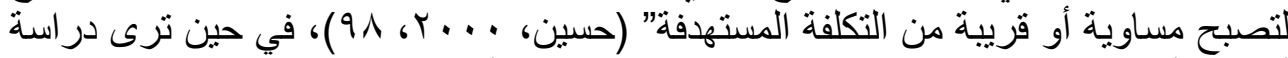

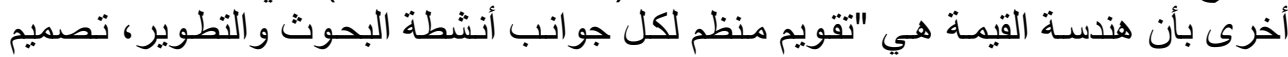

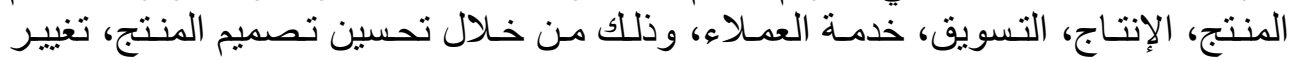

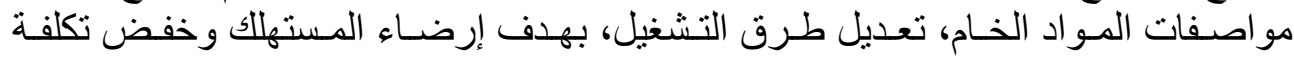

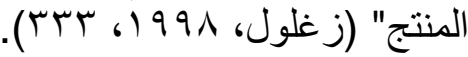

و يمكن توضيح مفهوم هندسة القيمة من خلال الثكل ) 


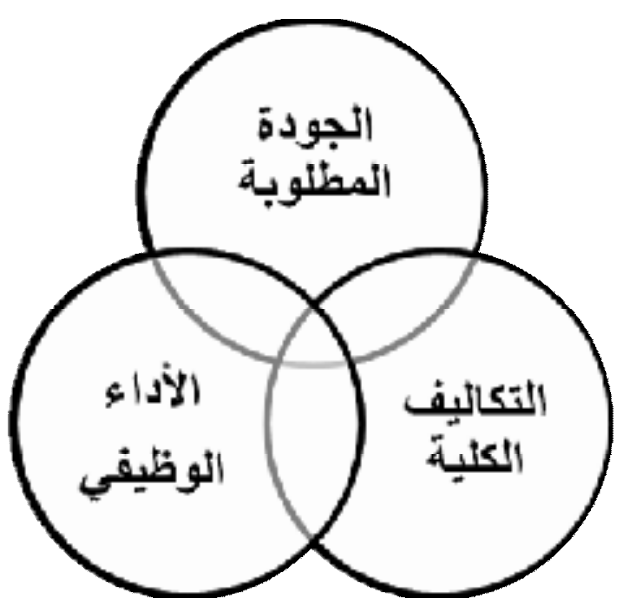

الشكل

مفهوم هندسة القيمة

المصدر: النموذج من تصميم الباحث

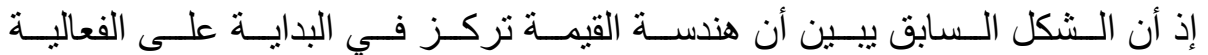
(Functions) عن طريق تحليل الوظائف (Effectiveness) في الكفاءة (Efficiency) عبر تحديد معايير الجودة (Euality) التي تجعل من المنتج أكثر

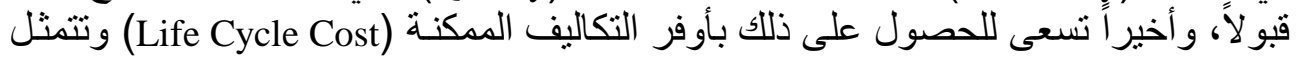
أهداف مدخل هندسة القيمة: القيول ويمكن تحديد أهداف هذا المدخل من خلافل مجمو عة من النقاط و التي تتمثل بما يأتي:

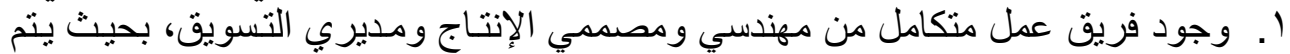

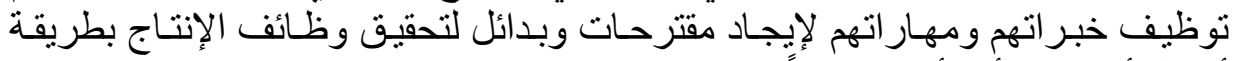

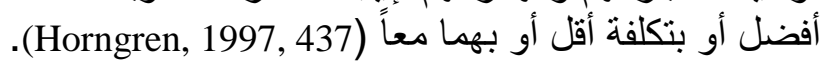
r. . الدر اسة والتعمق في فهم متطلبات واحتياجات العملاء و وعدم إغفال أب منها أثناء مرحلة التصميم للمنتج (Sakurai,1989, 44).

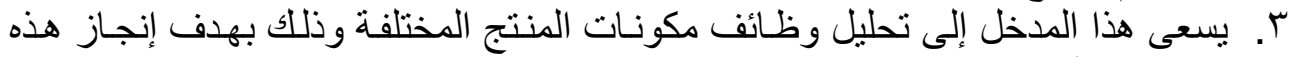

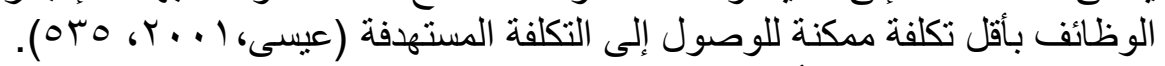

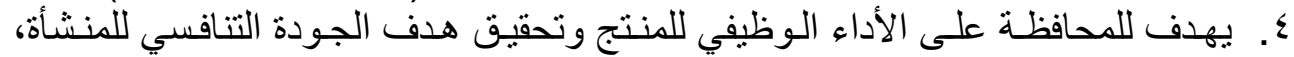

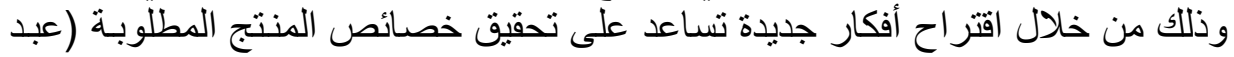

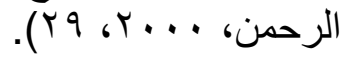

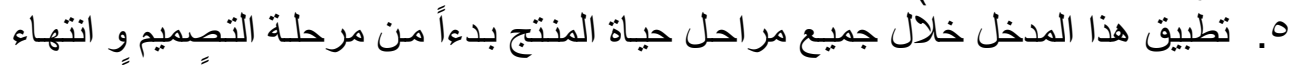

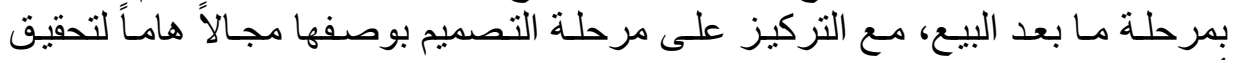

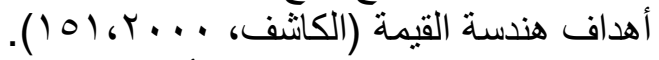

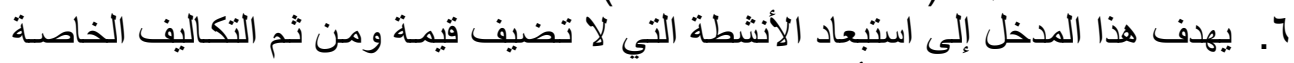

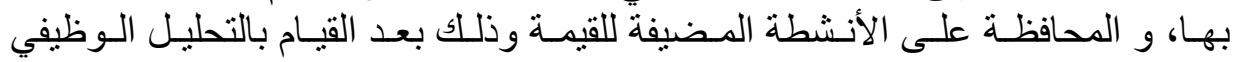
لمكونات المنتج (Kato,1993, 43). 


\section{[199] القطيني}

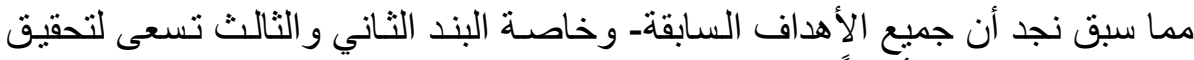
رغبات المستهلك- وتسعى أيضاً في مجملها لتخفيض التكلفة وبالتالي تحقيق الميزة التنافسية التي تسعى إليها المنشأة.

\section{r. التحسين المستمر للجودة}

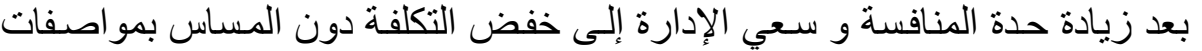

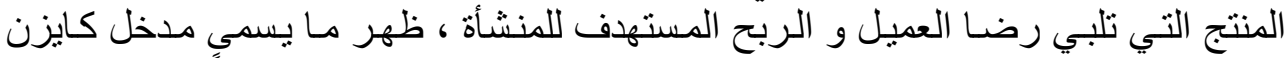

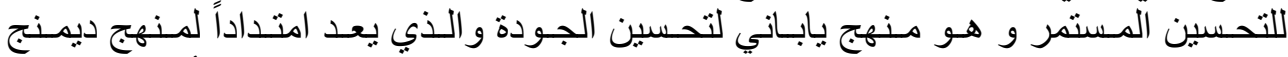

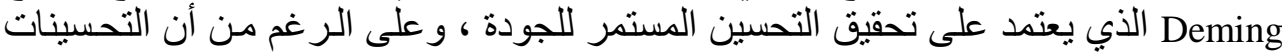

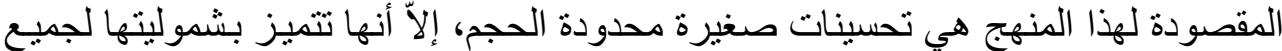

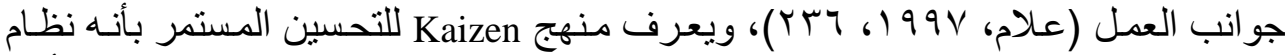

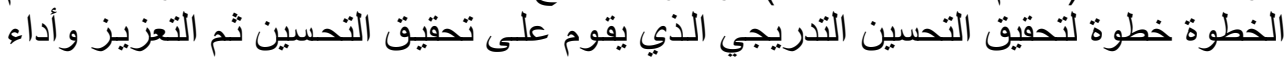

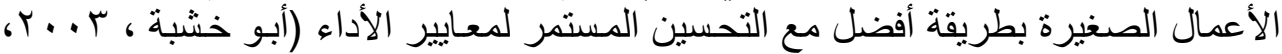

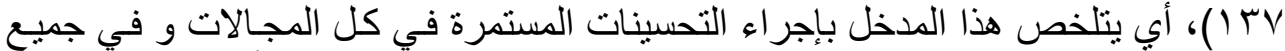

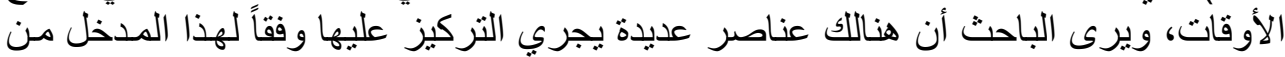

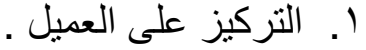

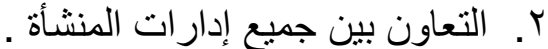

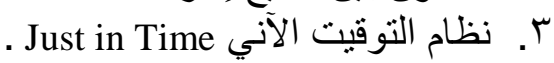

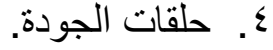

$$
\begin{aligned}
& \text { ه. علاقات الإدارة مع العاملين. } \\
& \text { 7. استخدام التطور التكنولوجي في العمل . }
\end{aligned}
$$

وقد عرف Monden and Hamada مدخل كايزن على أنه "النظام الذي يدعم عمليات تخفيض التكاليف خلال مر احل التصنيع و الإنتاج و ذللك على مستوى منتج قائم". ويمكن التهن

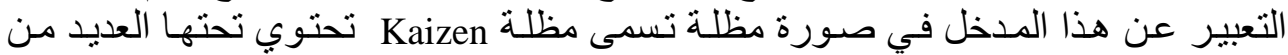
أساليب التحسين المستمر (Davies and Boczko,2005, 34) : 


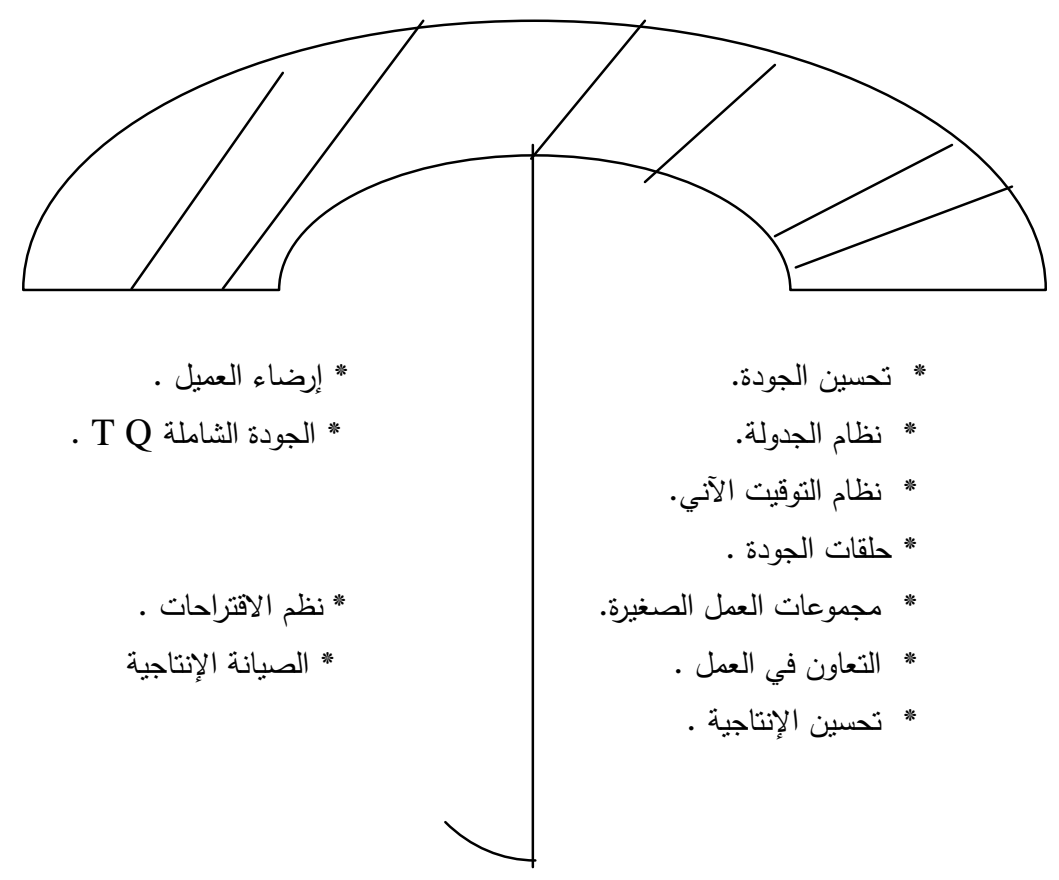

The Kaizen Umbrella

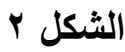

ويستخدم أسلوب Kaizen للتحسين المستمر لتلافي (السلمي، 999 (، 999):

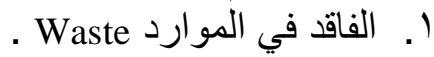

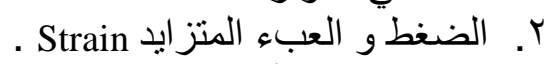

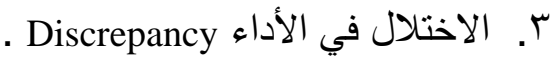

كما ويعد مدخل Kaizen نتيجة التطور الذي طر أ على المحاسبة الإداريـة واستخدامها

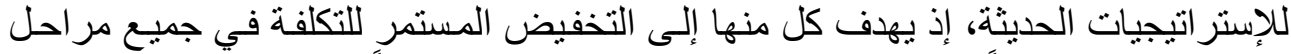

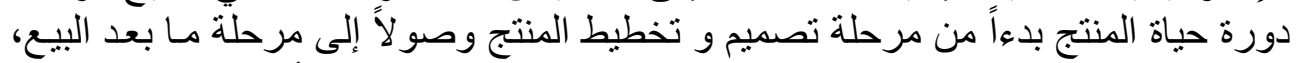

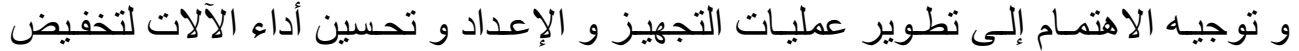

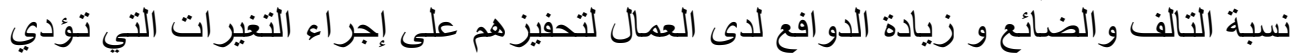

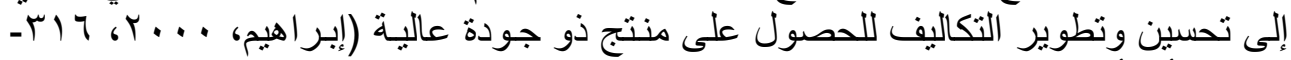

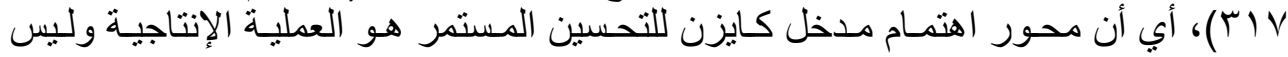

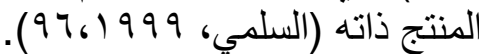
ومما سبق يخلص الباحث إلى أن مدخل Kaizen للتحسين المستمر يساعد في تحقيق

مدخل التكلفة المستهدفة من خلاف الإل عدة مجالات الات منها: ا . تحسين مستوى الأداء و الإنتاجية . 
r. ب. خفض الآثار الناجمة عن مسببات التكلفة .

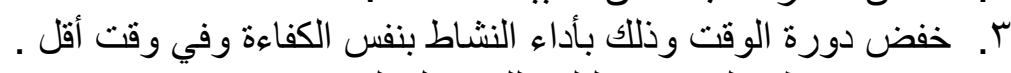

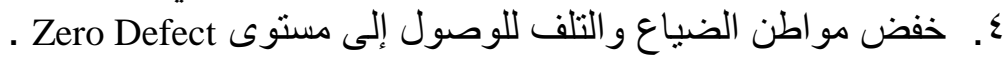
○. خفض الأنثطة والعمليات التي لا تؤدي إلى تحسين الجودة والأداء الوظيفي للمنتج.

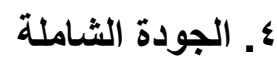

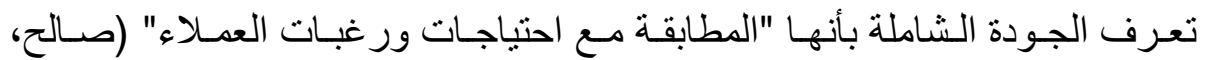

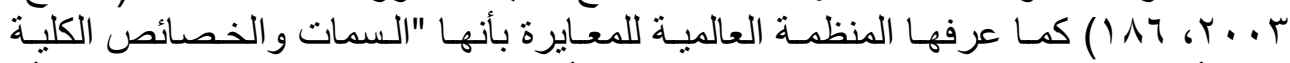

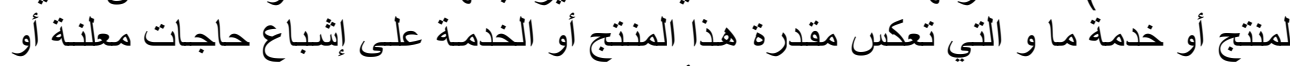

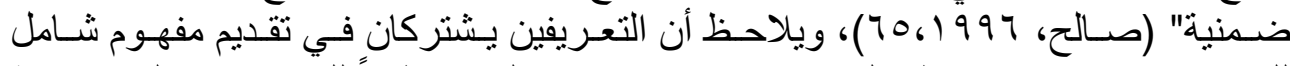
للجودة حيث لا تعنى فقط بالتحقق من إتقان تصنيع المنتج طبقاً للمو اصفات التهات الموضوعة

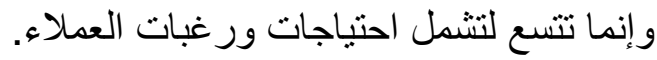

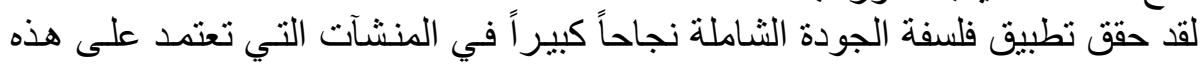

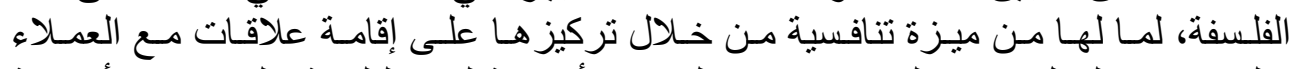

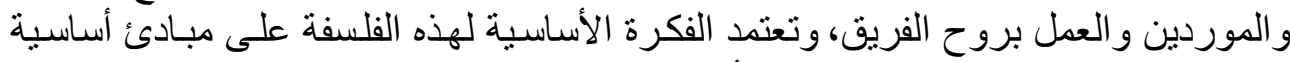

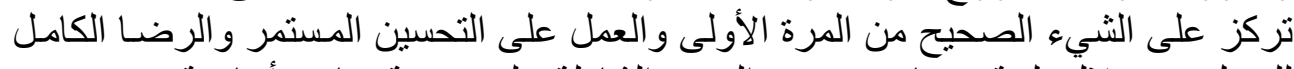

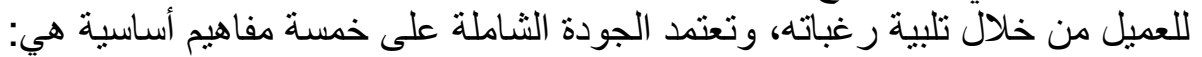

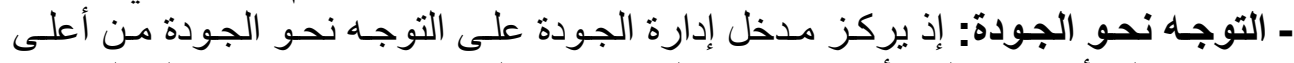

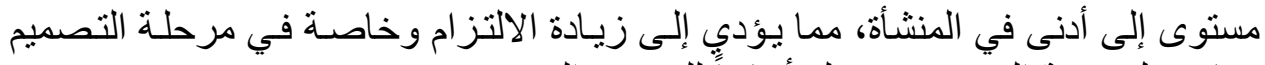

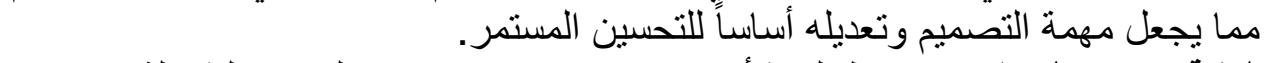

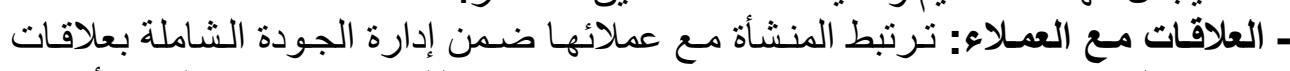
مباثرة لتحديد احتياجاتهم وفهم مدى نجاحها في إثباع تلكاتلك الاحتياجات و القيام بأنشطة التطوير اللازمة لذلك.

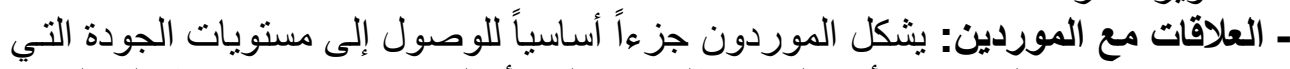

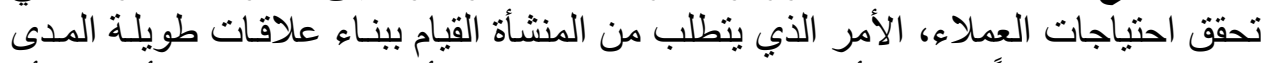

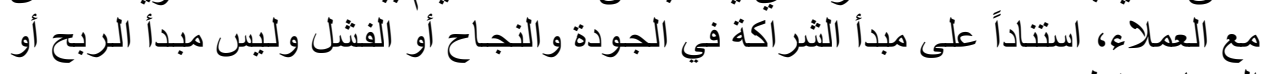

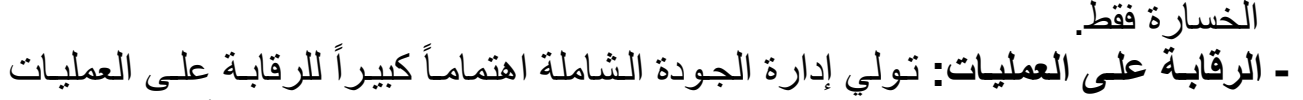

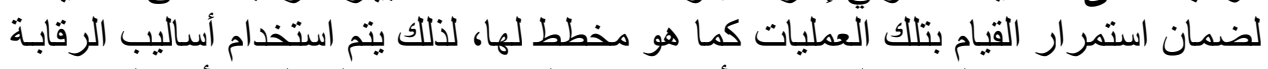
الإحصائية وخر ائط الجودة التي يجب أن يتدرب على استخدامها العاملين الأمر الذي يزيد النيد

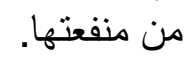

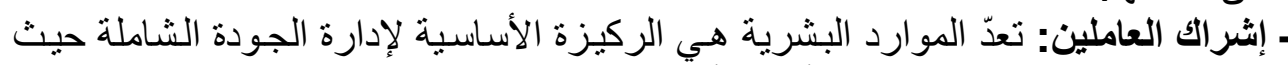

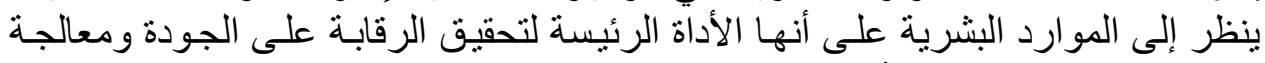

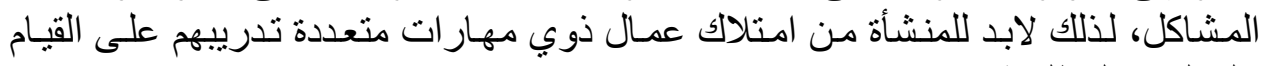
ويرى الباحث أن التوجه نحو الجودة الثاملة وفق مفاهيمها الأساسية يؤدي إلى إقامسة بالعمليات المطلوبة.

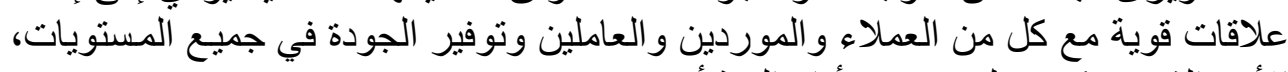
الأمر الذي ينعكس على تحسين أداء المنشأة. 


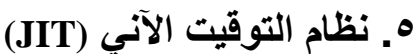

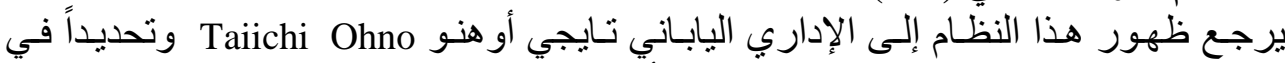

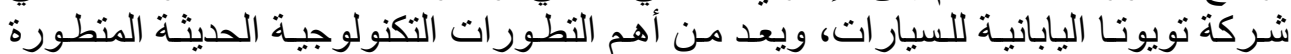

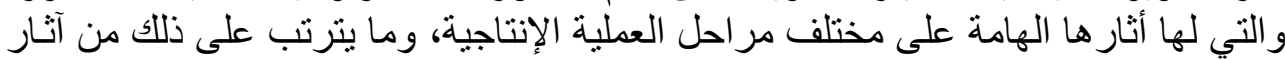
هامة على عناصر تكاليف المنتجات النهائية النائ.

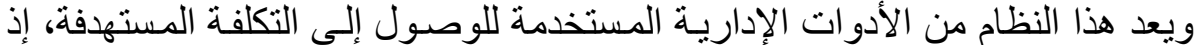

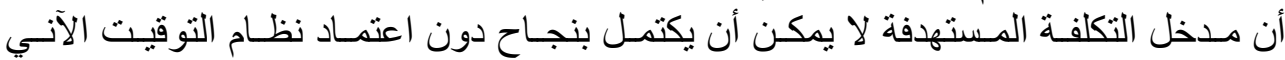

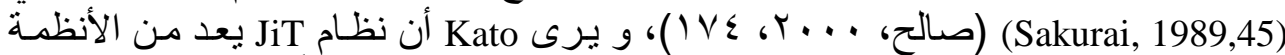

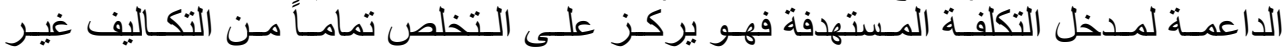

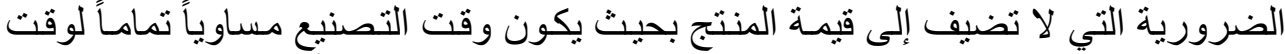

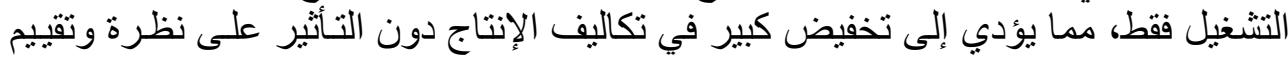

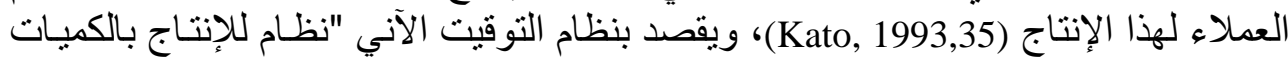
وفي الوقت المناسب لمو اجهة طلب مستقر يُينى على نظام دقيق للتحكم في المخزون و نظام

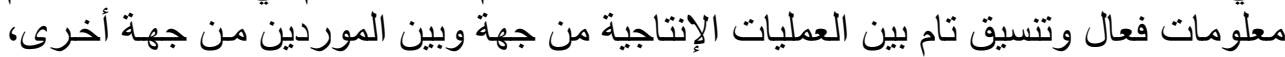

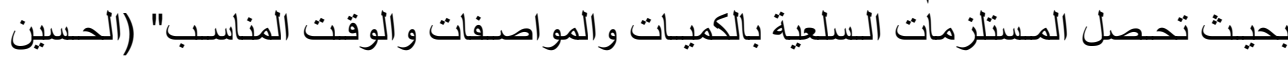

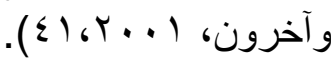

كما يتطلب تطبيق نظام التوقيت الآني توافر عدة عناصر أساسية تتمثل في (عطية،

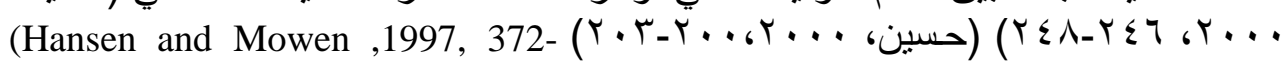

ا. اعتماد المنشأة على عدد محدد من الموردين الذين ثبت بالتجربة إمكانية الاعتمـاد عليهح

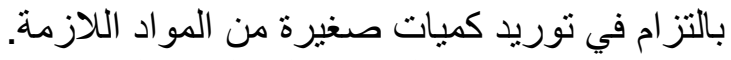

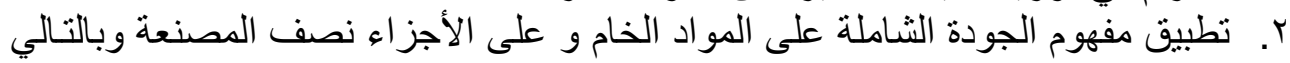
على المنتجات التامة.

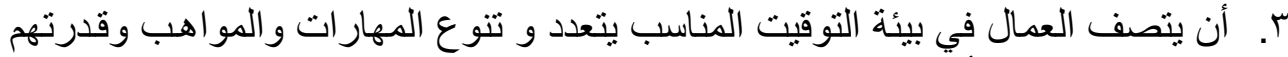

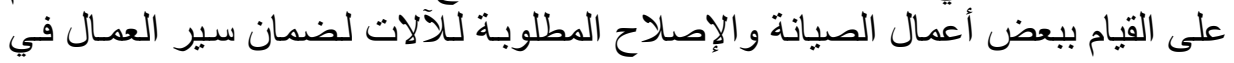

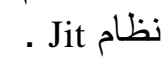

ع. تبسيط أنشطة الإنتاج بحيث يتم التعرف على الأنشطة التي تضيف قيمـة والأنشطة التي

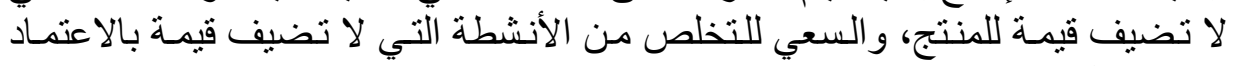
على مدخل هندسة القيمة.

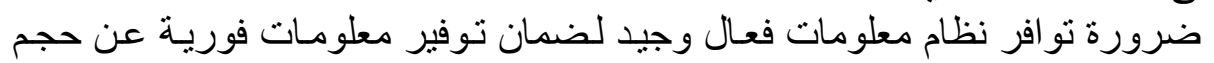
الإنتاج المطلوب في كل نشاط.

\section{ثالثاً. أثر الإدارة الإستراتيجية على المحاسبة لتدعيم الميزة التنافسية} / / مفهوم الميزة التنافسية الإدئية

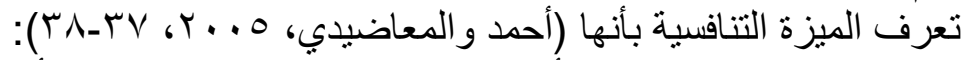

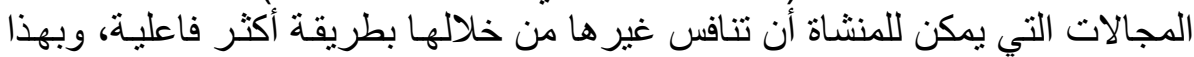

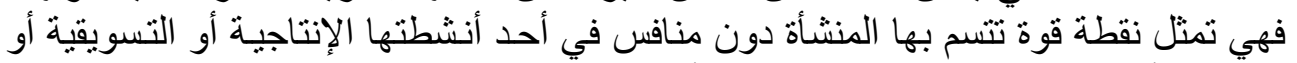
التمويلية أو فيما يتعلق بمواردهـا البشرية أو الموقع الجغر افي لها، وهي أنهي تعتمد على نتائج 
فحـوص وتحليل كل مـن نقاط القوة والضعف الداخليـة، فضلاً عن الفرص و والمخـاطر

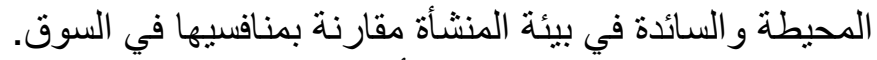

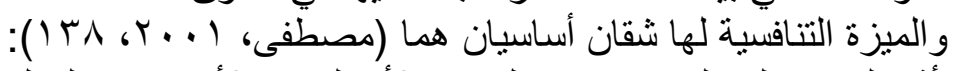

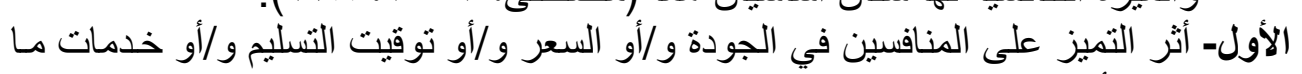

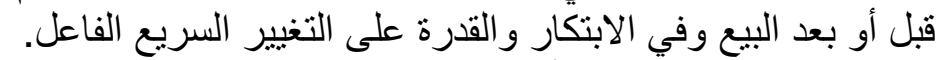

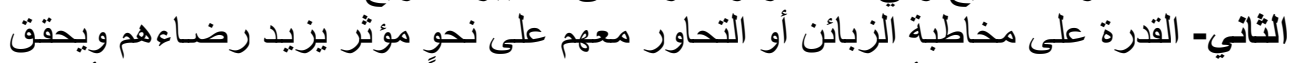

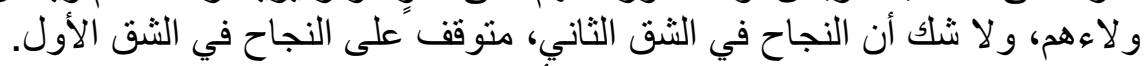

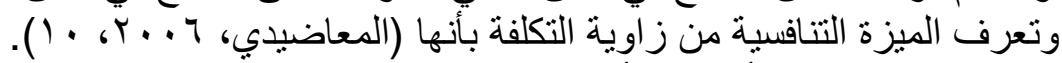

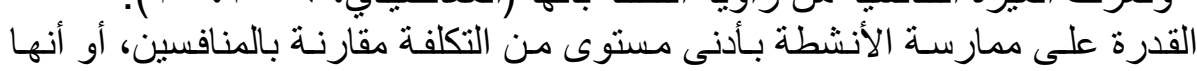

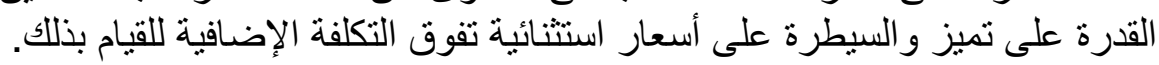

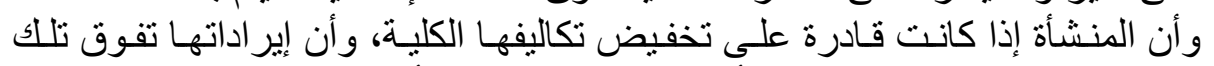
التكاليف فسوف تحقق ميزة توفير قيمة أعلى للزبون (متفرقة) أو تكلفة اقلى

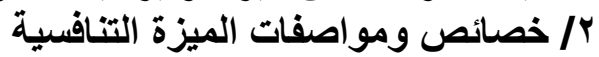

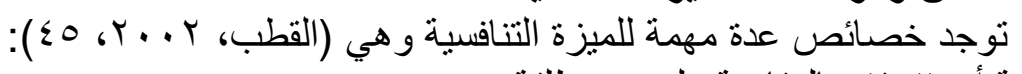
- نسبية أي تتحقق بالمقارنة وليست مطلقة. - تحقق التفوق و الأفضلية على المنافسين.

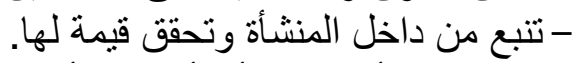

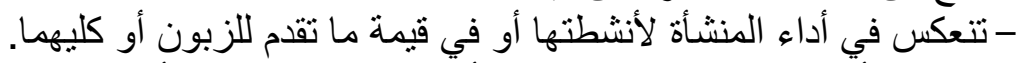

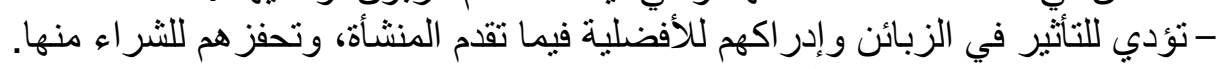

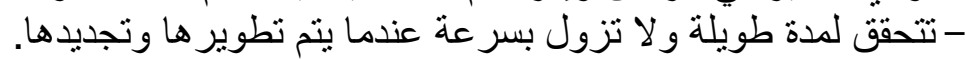

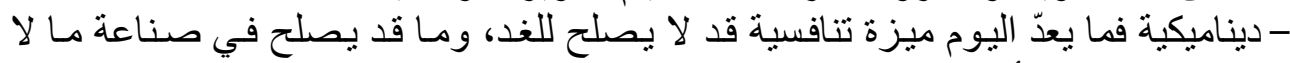
ويؤدي حصول المنشأة على ميزة تنافسية إلى نتـائج عديدة أهمها (الربيعـاوي،

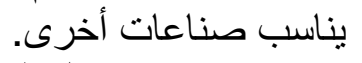

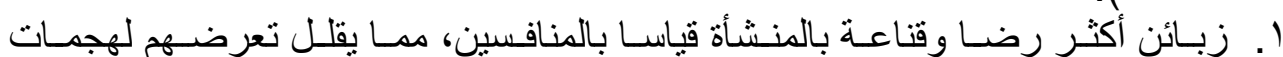
و وعروض المنافسين.

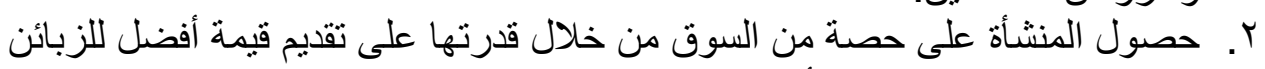

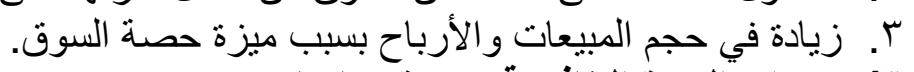
ب/ محددات الميزة التنافسية ودورة حياتها

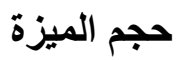

يعد حجم الميزة التتافسية من أهم المحددات المؤثرة في ديمومـة واستمرار الميزة

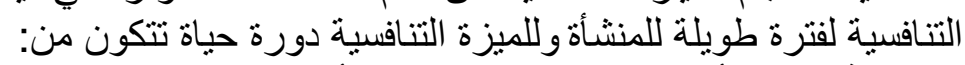

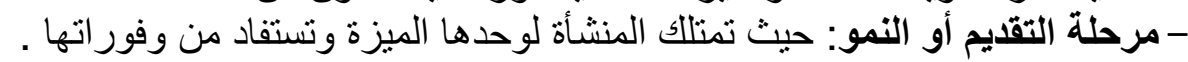

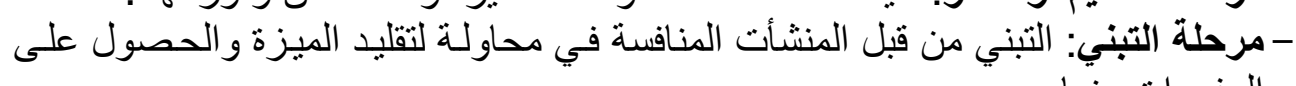

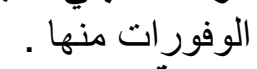

- مرحلة التقليد/ الركود: في حالة قيام المنشآت المنافسة بتقليد ومحاكاة الميزة التنافسية

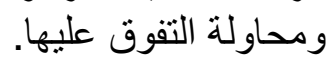




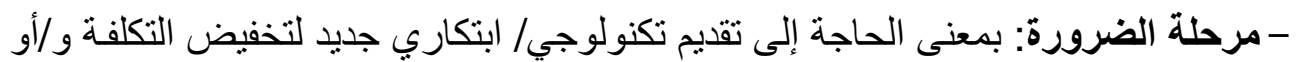
تدعيم ميزة تميز المنتج ـ و هنا تبدأ المنشأة في تطوير أو تجديد أو أو تحسين الميزة الحئل الحالية،

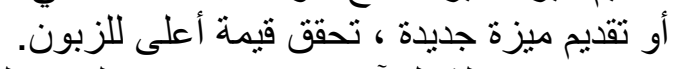

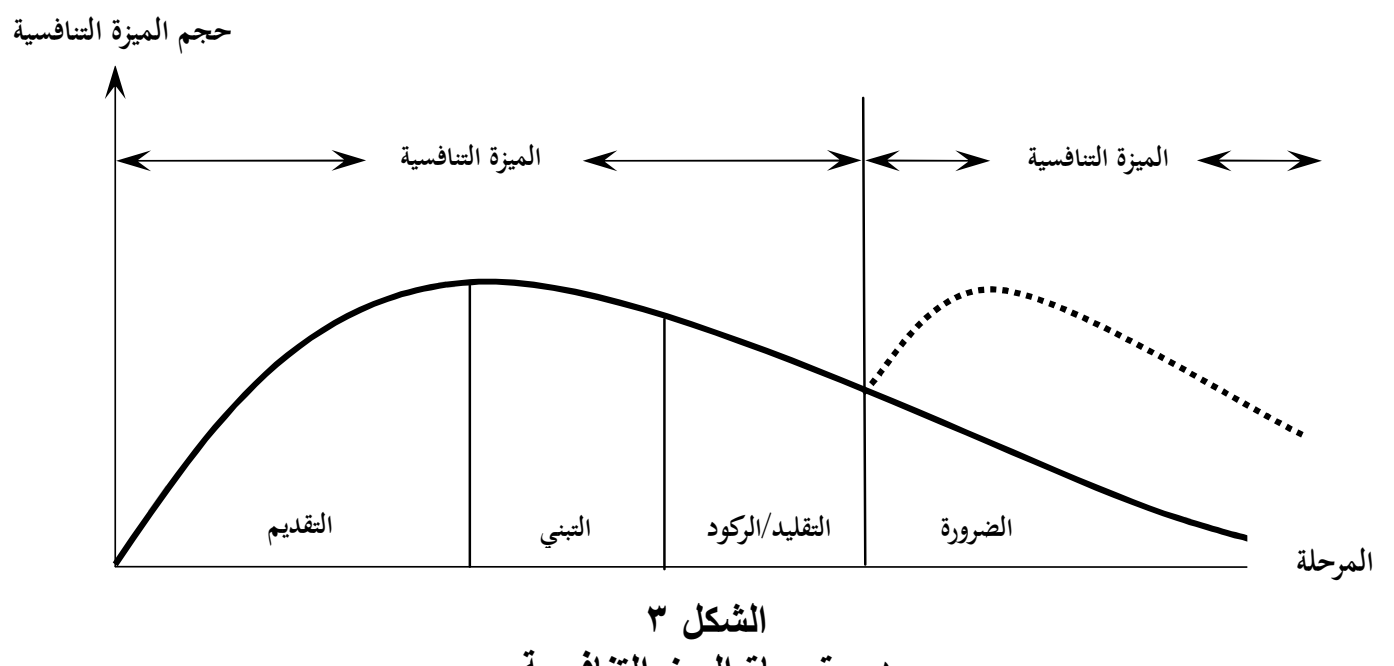

دورة حياة الميز التنافسية

المصدر: خليل، نبيل مرسي،(1999) ص4ه.

\& / مصادر الميزة التنافسية ومعايير الحكم على جودتها وتعزيز الميزة

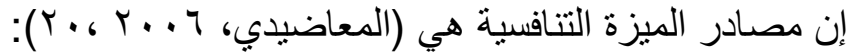

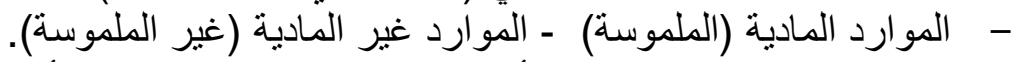

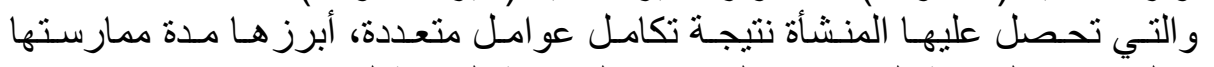

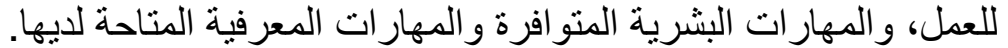

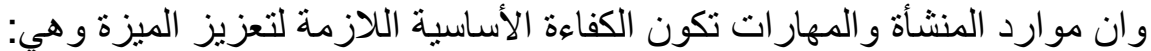

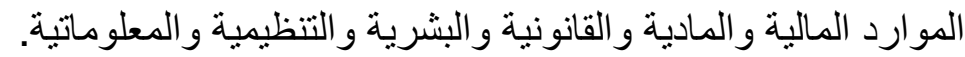

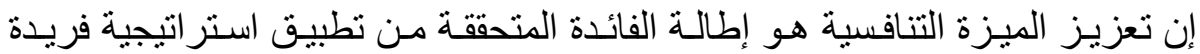

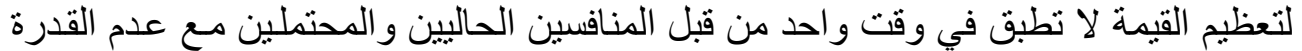

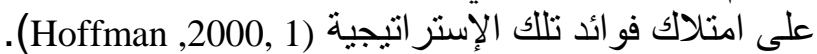

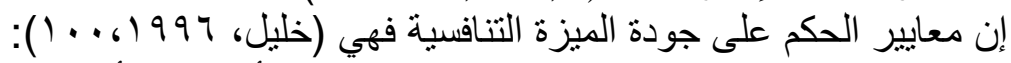
1 ا. مصدر الميزة: هل هي مرتبطة بإستر اتيجية قيادة التكلفة أم التمايز أم التركيز؟

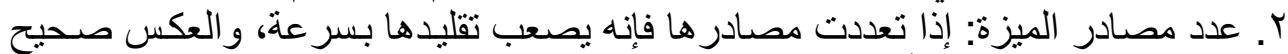

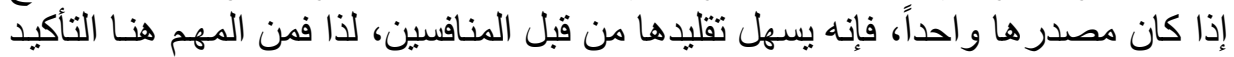

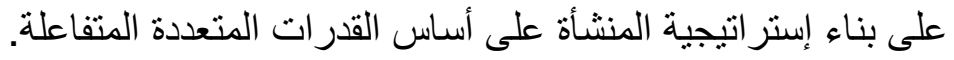

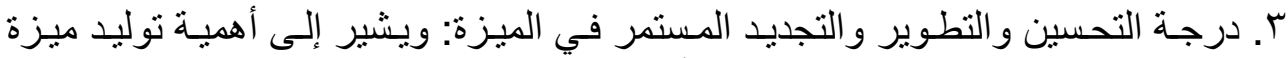

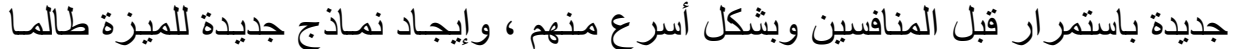

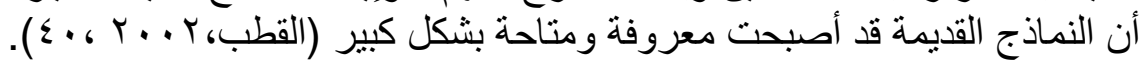




\section{القطيني[r.0}

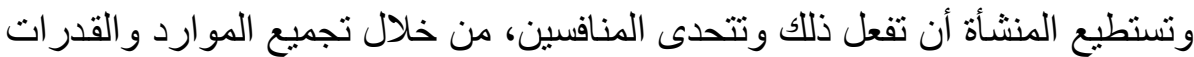

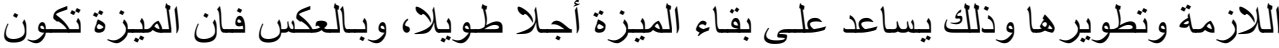

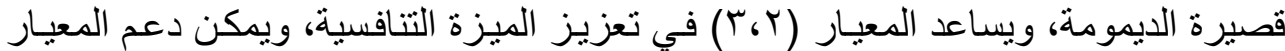

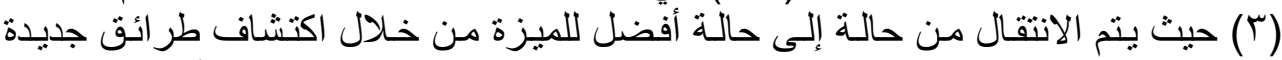

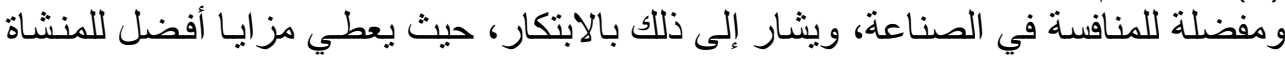

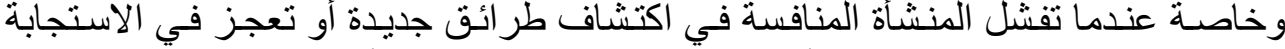
للتحو لات البيئية المختلفة، ويمكن أن يشكل ذلك ميزة المتحرك الأول التها الذي الذي يستجيب للتغيير

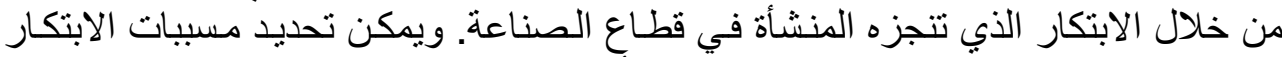

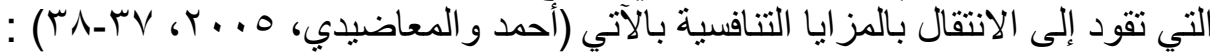
- تقنيات جديدة. - حاجات جديدة أو متحولة للزبائن. - ضرورة التجديد في تقسيمات الصناعة التهات - الانتقال أو التحول بتكلفة المدخلات. - التغير ات في التشريعات الحكولية.

\section{ه/ دور أسـاليب الإدارة الإسـتراتيجية في دعم الإسـتراتيجيات التنافسية وتعزيـز الميزة التخافسية أنيالية}

ا ـ دور أساليب الإدارة الإستراتيجية في دعم إستراتيجية قيادة التكلفة

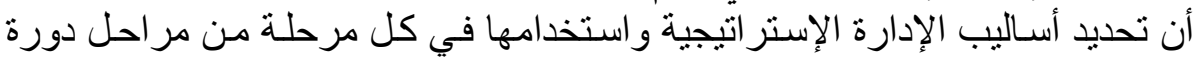

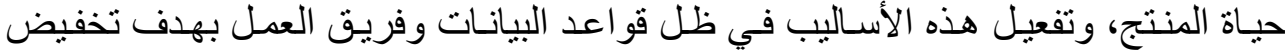
التكاليف (مسع المحافظة على منطلبـات الزبون في المنتج)، يدعم إستر اتيجية قيادة التكلفة

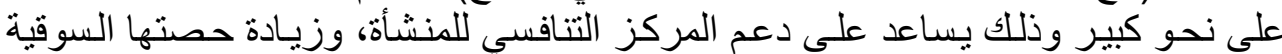

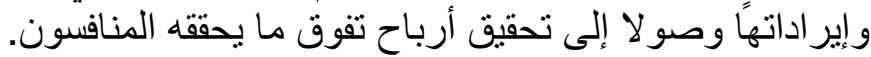

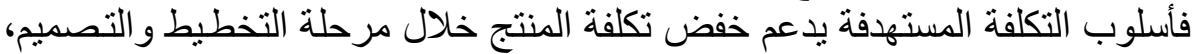

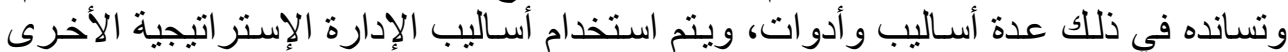

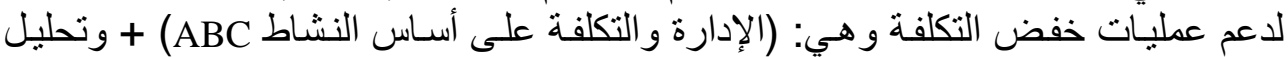

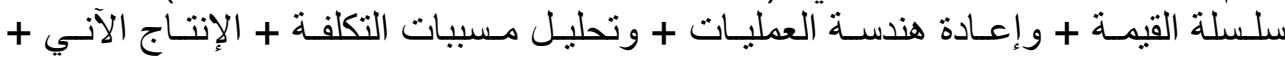

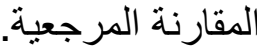

أما في مرحلة الإنتاج فيتم استخدام أسلوب التحسين المستمر ويسانده في دعم هذه التها

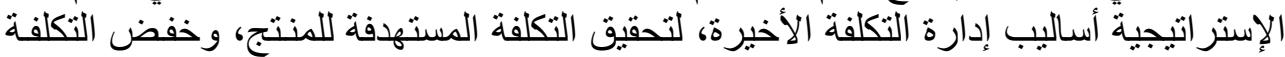

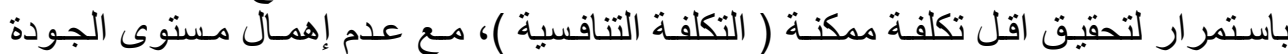

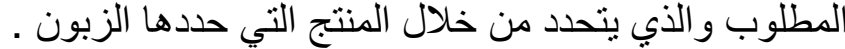

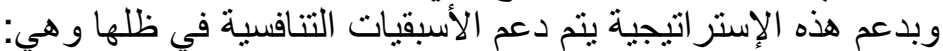

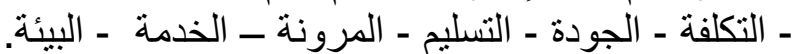

r. دور أساليب الإدارة الإستراتيجية في دعم إستراتيجية التمايز

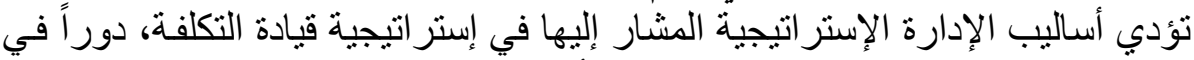

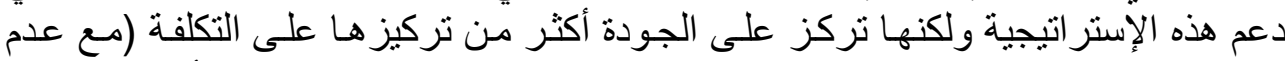
إهمال عنصر التكلفة ودوره في هذه الإستر اتيجية)، فهي تهدف إلى تحقيق تركئ أعلى مستوى 


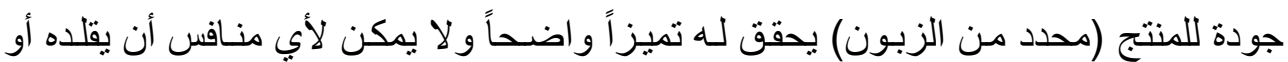

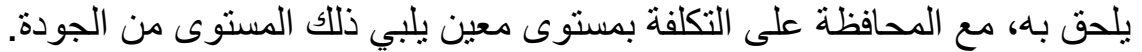

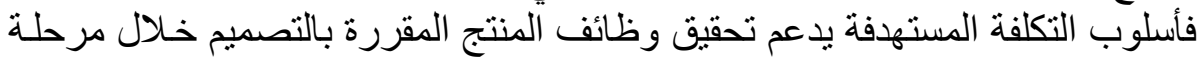

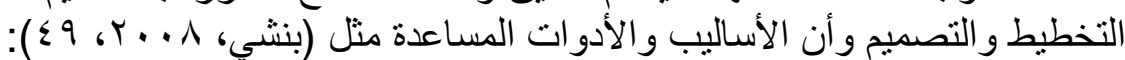

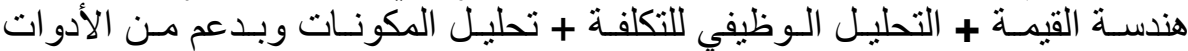

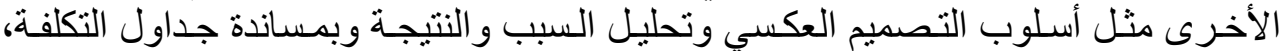

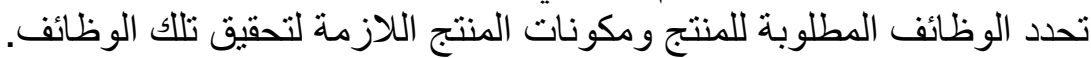

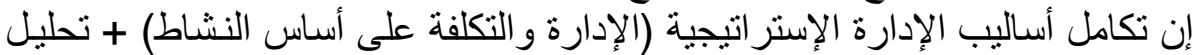

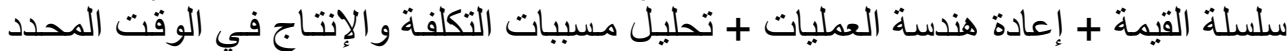

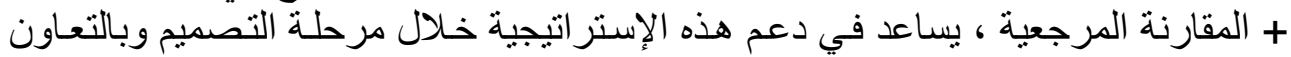

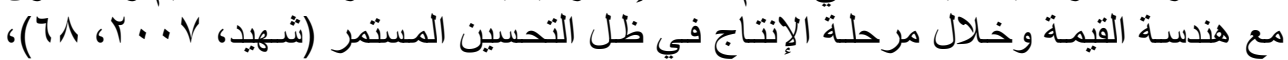

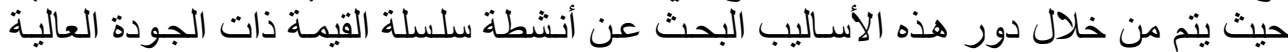

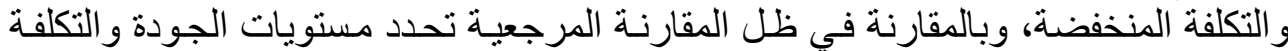

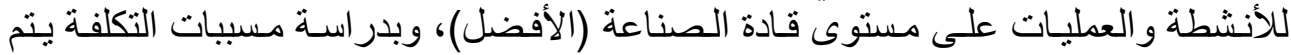

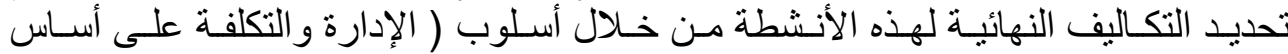

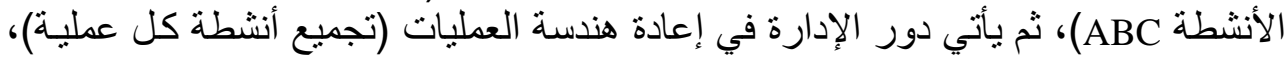

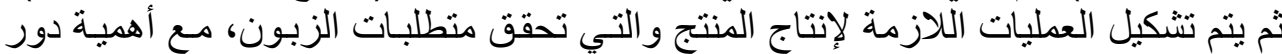

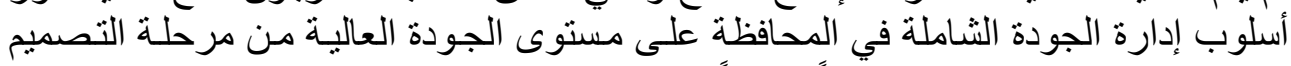
حتى مرحلة ما بعد البيع، تخطيطاً وتنفيذاً.

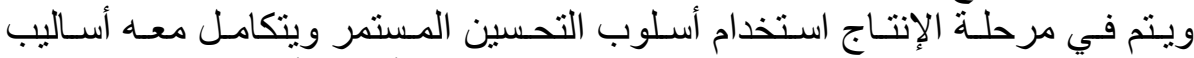

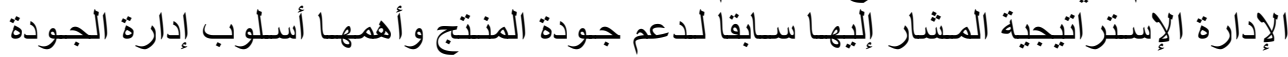

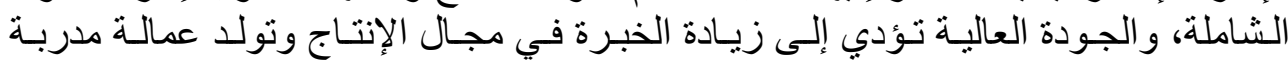
تدريب عالي، مما يؤدي إلى خفض تكاليف الإنتاج و تحسين رضيال الإنا الزبون، وزيادة أرباح

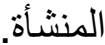

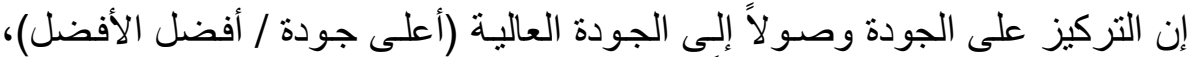
يعد هدف هذه الإستر اتيجية، ويسهم كثير أ في تعزيز الميزة التنافسية أو الأسبقيات التنافسية.

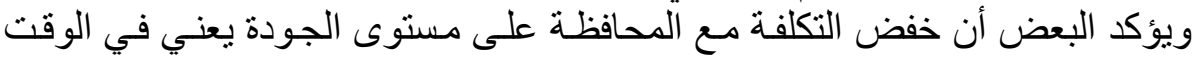
نفسه خفضا آخر للتكلفة، إذ أن تحقيق الجودة يقلل من تكاليف عدم الجودة (عبد الرحمن، الترف

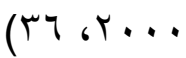

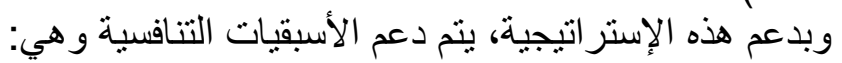
ـ الجودة - المرونة الخدمة - البيئة - التكلفة.

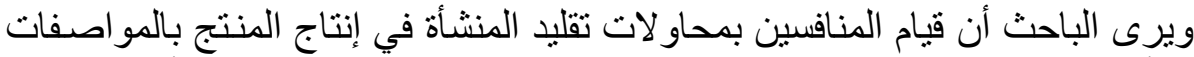

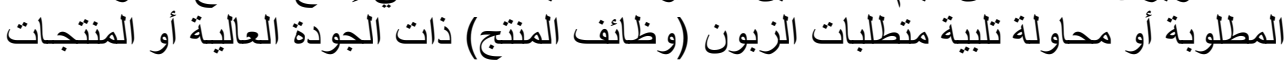

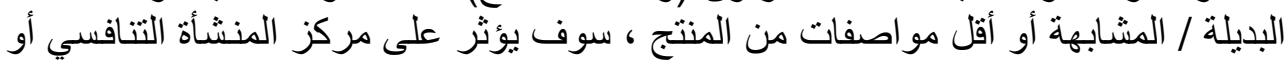

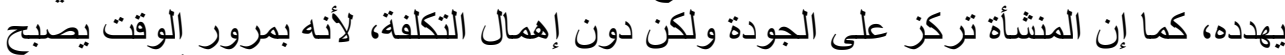

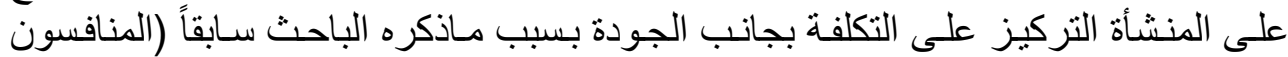

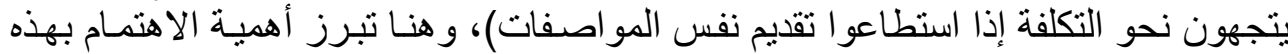

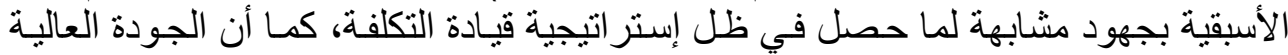

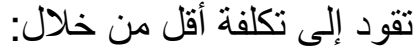




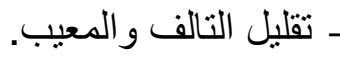

- خفض تكاليف إعادة التثتغيل للمرتجع.

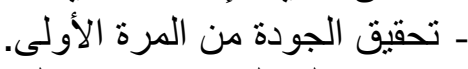
- مبر ات العاملين ومهار اتهم المتز ايدة.

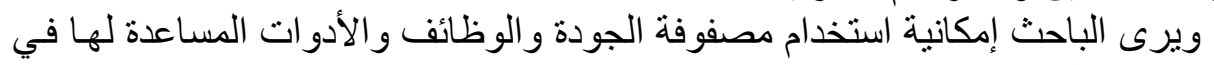
دعم أسبقية التكلفة ضمن إستر اتيجية التمايز .

رابعاً- الاراسة التطبيقية

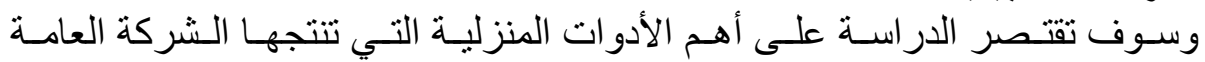

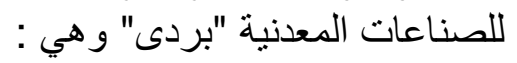

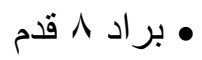

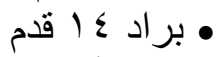

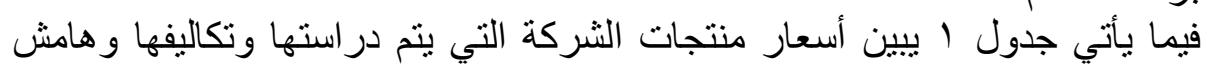
ربحها:

\begin{tabular}{|c|c|c|c|c|c|c|c|c|c|c|}
\hline & & & & كة & ول 1 & اسعار منا & & & & \\
\hline & مالية & & للموزعبة الربح & & للألمسة & للموزعبة & لمبتسبة & & المنتّ & \\
\hline & 1.49 & & $\varepsilon . \wedge 9$ & & .19 & $1 . \varepsilon \ldots$ & $11 \ldots$ & & براد 1 & \\
\hline & 171 & & 0 & & $\because 0$ & $17 \lambda \ldots$ & $1 \vee \wedge$. & & بر ادـا & \\
\hline & & & & & & & & رة السور & فام باللير & * الأ \\
\hline & 5 & & الإجمالّ & الجاه & ة الإن & تنفيذ . & يوضح مـ & الآتي r & الجدول & \\
\hline & & & الىى & هز الا & تاج الد & ذ خطة الج الج & معدل تت & & & \\
\hline & ك التنفيذ: & & فعلي & ج الجاهز & & الإجمالي & جاهز المخط & الإنتاج & & \\
\hline & & ه & & & ك & & & a & الوحدة & المنتج \\
\hline متغيرة & ثابتة & & متغيرة & ثابتة & & متغيرة & ثابتة & هي & & \\
\hline$\% 99$ & $\% 90$ & $\% 90$ & $\{V \mid \varepsilon$ & sor & 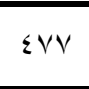 & $\leqslant$ Vo. & $\leqslant V \leqslant 9$ & o.. & بر اد & براد 1 \\
\hline$\% 10$ & $\% 10$ & $\% 10$ & $r \leq 1 \leq$. & KrITA & ד & $101 \ldots$ & $101 \ldots$ & $1 \ldots$ & براد & بر ادـ 1 \\
\hline
\end{tabular}

والجدول الآتي ؟ يوضح الفجوة بين التكاليف الفعلية والتكاليف المستهدفة: 


\begin{tabular}{|c|c|c|c|c|}
\hline \multicolumn{5}{|c|}{ الفجوة بين التكاليف الفعلية والتكاليف } \\
\hline المستهدف & فجوة التكلقة & المستهدفة & التكلفة الفعلية & المنتج \\
\hline $1 \ldots$ & 90.11 & $1 . r \ldots$ & 1.190 .11 & بر اد ^ قدم \\
\hline $1 \ldots$ & 90 & $178 \ldots$ & 17890 & بر ادئ ( قدم \\
\hline
\end{tabular}

يتم تحديد فجوة التكلفة بالنسبة لكل منتج من خلال الجدول ؟:

\begin{tabular}{|c|c|c|c|c|c|c|c|c|c|c|}
\hline \multicolumn{11}{|c|}{ تحديد فجوة التكلفة بالنسبة لكل منتج } \\
\hline \multicolumn{2}{|c|}{ تسبة التقفيض } & \multicolumn{2}{|c|}{ قجوة الاتكلة للنتنع } & \multicolumn{2}{|c|}{ التكالبف النستيائة } & \multicolumn{2}{|c|}{ 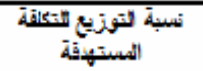 } & \multicolumn{2}{|c|}{ الثئليف القعلبة للكتيع } & \multirow[b]{2}{*}{ التنع } \\
\hline 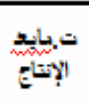 & تار،الإتصنيج & الإنتاج & 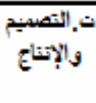 & 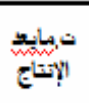 & 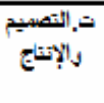 & 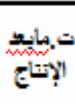 & 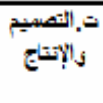 & تالث، با بط & تولالتصنيج & \\
\hline$\% \cdot .01$ & $\% \cdot . \Delta$ & $\frac{1.1 T}{1 T}$ & $94 . \wedge$ & $r+r . r T$ & 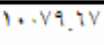 & $T r$ & 91,1 & rrr.tr & $1.16 r$ vo & 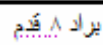 \\
\hline$\% .91$ & $\% \cdot .9$ & $r . r$ & $9 \% .4$ & 198.12 & $170+r .10$ & $r .1$ & 98.9 & $191 . \mathrm{rV}$ & $19099 \mathrm{VT}$ & 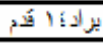 \\
\hline
\end{tabular}

نسبة التخفيض = فجوة التكلفة للمنتج ب التكاليف الفعلية للمنتج نسبة التوزيع للتكلفة المستهدفة = التكاليف الفعلية للمنتج في كل مرحلة بـ إجمـالي التكلفة الفعلية

\section{هـ التظلب على فجوة التكلفة}

ويتم عادة توزيع تكاليف كل منتج من منتجات الثركة الثرة على مرحلتين هما: 1 ا ـ تكاليف مرحلة التصميم و الإنتاج. r r باليف مرحلة ما بعد الإنتاج.

ويمر هذان المنتجان خلال هذه المرحلة داخل الصالة الأولى بمجموعة من الأنشطة

$$
\begin{aligned}
& \text { - سي: سحب المواد الأولية. } \\
& \text { - - تصنيع القطع نصف المصنعة. } \\
& \text { - - تصنيع الهيكل. } \\
& \text { - تصنيع الباب. }
\end{aligned}
$$

- ـ ويمكن تحديد الأسباب المتكررة التي تـؤدي إلى ارتفـاع التكلفة خـلال كل نشاط مـن الأنشطة السابقة وذلك باستخدام هيكل السمكة. 


\section{القطيني [r.9 [}

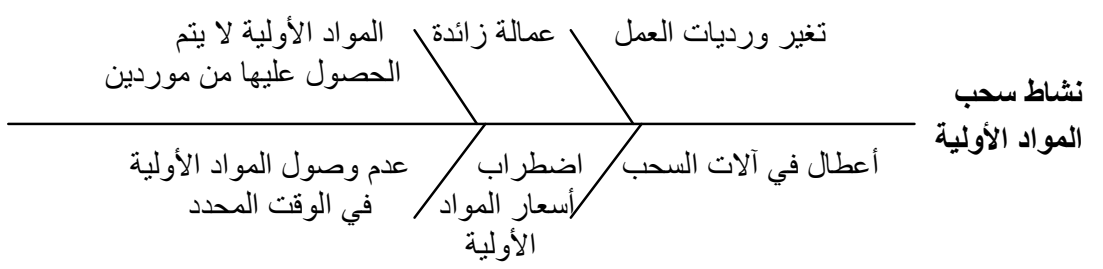

وبدر اسة هذه الأسباب التي تؤدي إلى ارتفاع التكلفة بالنسبة لهذا النشاط تبين أن أكثر

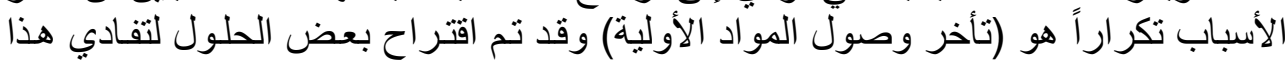

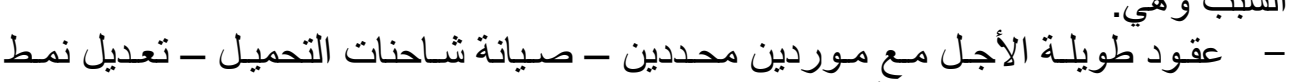

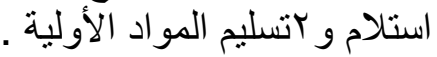
ويتم استخدام مصفوفة الحلول لاختبار الحل الأمثل لهذا النشاط:

\begin{tabular}{|c|c|c|c|c|c|}
\hline الحل الثالث & الحل الثاني & الحل الأول & الأهمية & & المعيار \\
\hline $\begin{array}{c}\varepsilon \\
1.5\end{array}$ & $\begin{array}{l}0 \\
1.0\end{array}$ & $\begin{array}{c}r \\
.9\end{array}$ & $\%$ \%. & 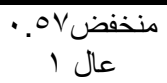 & تكلفة الحل \\
\hline $\begin{array}{c}r \\
.9\end{array}$ & $\begin{array}{l}r \\
. .7\end{array}$ & $\begin{array}{l}0 \\
1.0\end{array}$ & $\%$ \%. & عالهف & كفاءة الحل \\
\hline $\begin{array}{l}\varepsilon \\
. \wedge\end{array}$ & $\begin{array}{l}\varepsilon \\
\cdot . \wedge\end{array}$ & $\begin{array}{l}r \\
\cdot . \varepsilon\end{array}$ & $\%$ \%. & 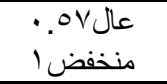 & احتمال النجاح \\
\hline $\begin{array}{c}7 \\
.7\end{array}$ & $\begin{array}{l}0 \\
.0\end{array}$ & $\begin{array}{l}0 \\
.0\end{array}$ & $\% 1$. & منخفض/OV. & إمكانية التطبيق \\
\hline $\begin{array}{l}0 \\
.0\end{array}$ & $\begin{array}{l}0 \\
.0\end{array}$ & $\begin{array}{l}\varepsilon \\
\ddots \varepsilon\end{array}$ & $\% 1$. & منخفض/OV. & قدرة العاملين \\
\hline$\varepsilon$ & $r .9$ & $r .0$ & & & الإجمالي \\
\hline
\end{tabular}

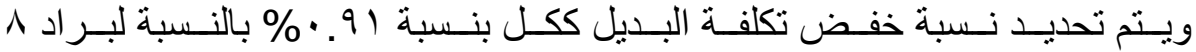

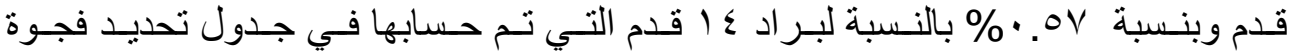
التكلفة وذللك من خلال المعادلة:

نسبة خفض التكاليف = فجوة التكلفة للوحدة ب التكلفة الفعلية للوحدة

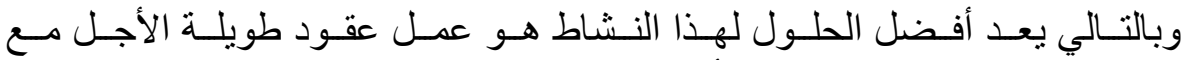

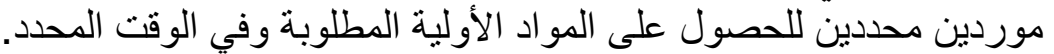

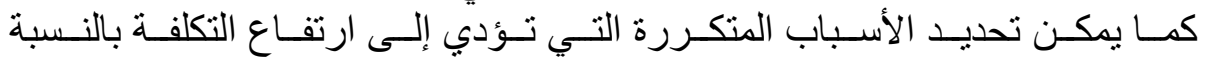




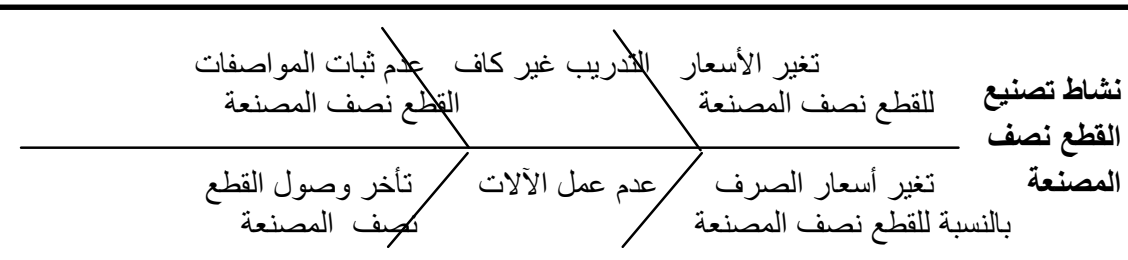

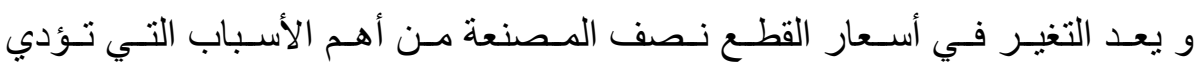

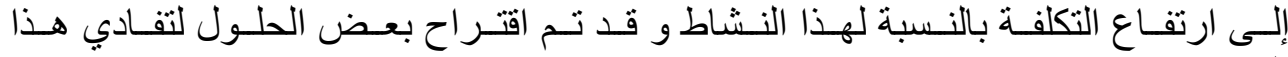

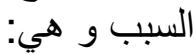

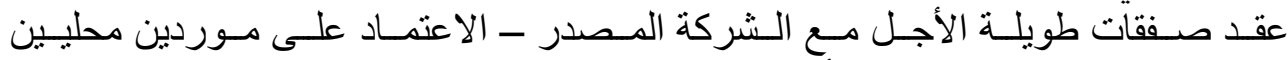

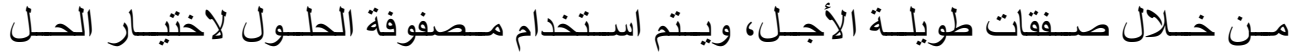

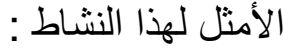

\begin{tabular}{|c|c|c|c|c|}
\hline الحل الثاني & الحل الأول & الأهمية النسبية & & المعيار \\
\hline $\begin{array}{l}\varepsilon \\
1 . Y\end{array}$ & $\begin{array}{l}1 \\
1.1\end{array}$ & $\% \Gamma$ & منذفض 10V. & تكلفة الحل \\
\hline $\begin{array}{l}r \\
.9 \\
\end{array}$ & $\begin{array}{l}0 \\
1.0\end{array}$ & $\%$ \%. & منذفضل & كفاءة الحل \\
\hline $\begin{array}{l}r \\
. \varepsilon\end{array}$ & $\begin{array}{l}0 \\
1\end{array}$ & $\%$ \% & 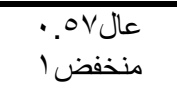 & احتمال النجاح \\
\hline $\begin{array}{l}\varepsilon \\
\ddots \varepsilon\end{array}$ & $\begin{array}{r}r \\
. r\end{array}$ & $\% 1$. & 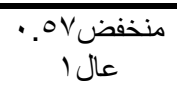 & إمكانية التطبيق \\
\hline $\begin{array}{c}r \\
r \\
r\end{array}$ & $\begin{array}{l}\varepsilon \\
. \varepsilon\end{array}$ & $\% 1$. & منخفضV0V & قدرة العاملين على \\
\hline$r .1$ & 0 & & & الإجمالي \\
\hline
\end{tabular}

* المصفوفة من إعداد الباحثي

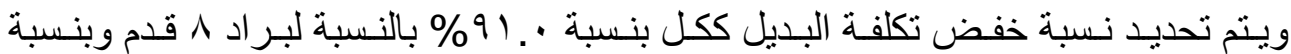

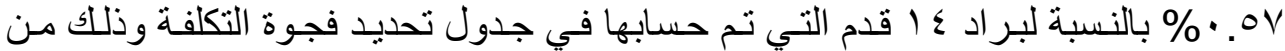

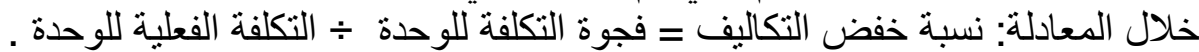

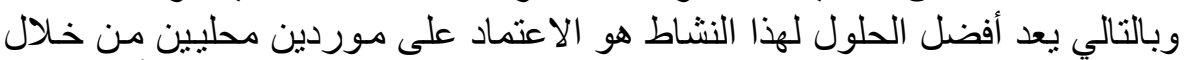

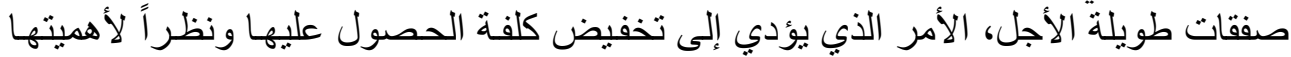
تحديد الأسباب المتكررة التي تؤدي إلى ارتفاع التكلفة بالنسبة لنشاطي تصنيع الهيكل

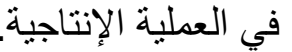

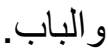

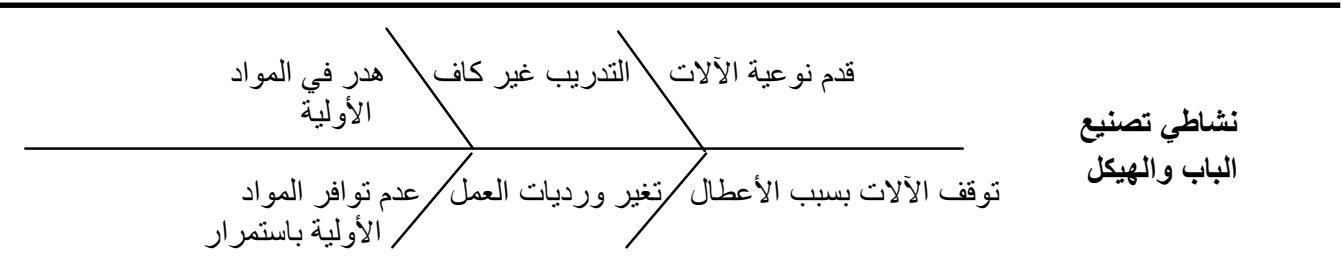




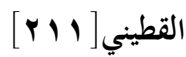

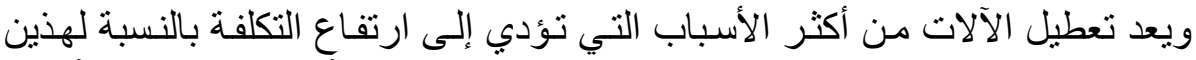

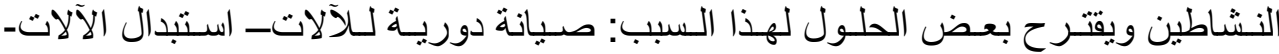
تدريب العمال ويتم استخدام مصفوفة الحلول لاختيار الحل الأمثل لهذا النشاط: لآل

\begin{tabular}{|c|c|c|c|c|c|}
\hline الحل الثالث & الحل الثاني & الحل الأول & الأهمية النسبية & & المعيار \\
\hline $\begin{array}{c}r \\
\ddots .9\end{array}$ & $\begin{array}{l}7 \\
1.1\end{array}$ & $\begin{array}{l}0 \\
1.0\end{array}$ & $\% ץ$ & منخفض مال IVV. & تكلفة الحل \\
\hline$\varepsilon$ & 1.1 & $\begin{array}{l}7 \\
1.1\end{array}$ & $\%$ \%. & عنخفضV & كفاءة الحل \\
\hline $\begin{array}{l}r \\
.7\end{array}$ & $\begin{array}{l}0 \\
1\end{array}$ & $\begin{array}{l}\varepsilon \\
\cdot \wedge\end{array}$ & $\% r$. & منخفضVا.0V & احتمال النجاح \\
\hline $\begin{array}{l}\varepsilon \\
\ddots \varepsilon\end{array}$ & $\begin{array}{l}0 \\
.0\end{array}$ & $\begin{array}{l}7 \\
.7\end{array}$ & $\% 1$. & 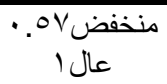 & إمكانية التطبيق \\
\hline $\begin{array}{l}r \\
. r\end{array}$ & $\begin{array}{l}\varepsilon \\
\ddots \varepsilon\end{array}$ & $\begin{array}{l}0 \\
.0\end{array}$ & $\% 1$. & منخفضV0V. & قدرة العاملين على \\
\hline r.s & 0.0 & 0.1 & & & الإجمالي \\
\hline
\end{tabular}

* المصفوفة من إعداد الباحث

ويعد أفضل الحلول لهذين النشاطين تدريب العاملين على استخدام الآلات بشكل

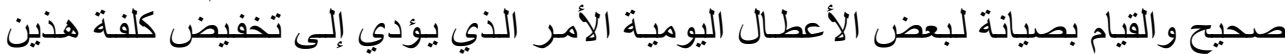
النشاطين النئن

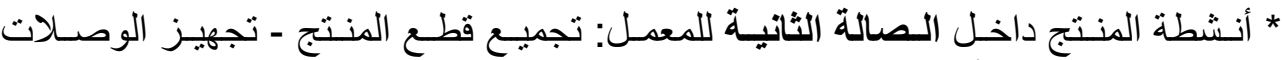

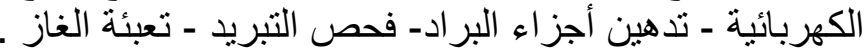

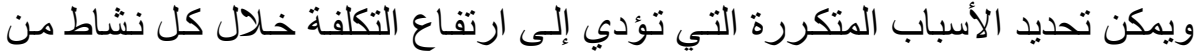

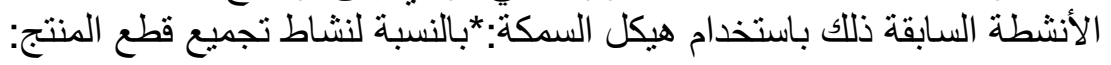

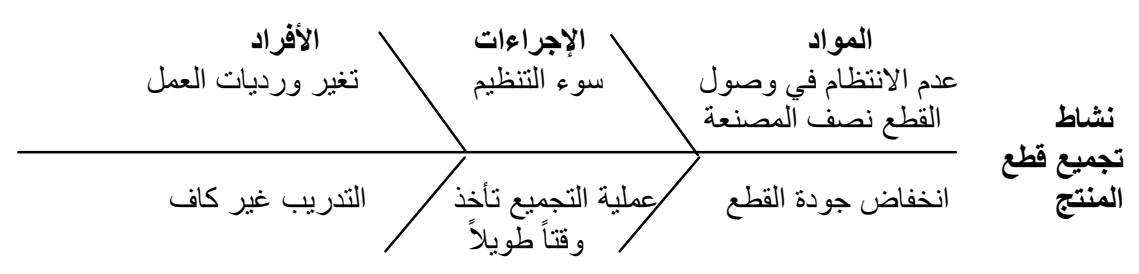

ويعد التنريب غير الكافي للعاملين من أكثر الأسباب التي تؤدي إلى ارتفاع التكلفة

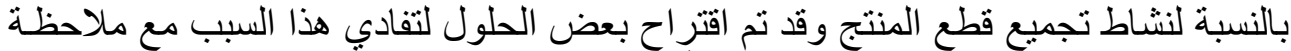

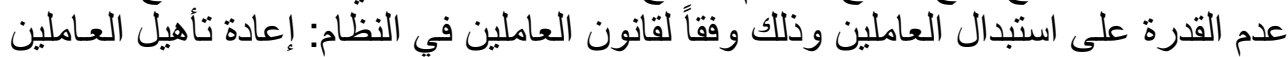
من خلال دورات تدرييية ـ الاستعانة بعاملين خبرة ـ الاستعانة بخبر اء أجانب أعانب. 


\begin{tabular}{|c|c|c|c|c|c|}
\hline الحل الثالث & الحل الثاني & الحل الأول & الأهمية النسبية & & المعيار \\
\hline $\begin{array}{l}7 \\
1.1\end{array}$ & $\begin{array}{l}0 \\
1.0\end{array}$ & $\begin{array}{c}Y \\
. .7\end{array}$ & $\%$ \%. & 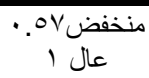 & تكلفة الحل \\
\hline$\varepsilon$ & $\begin{array}{l}0 \\
1.0\end{array}$ & $\begin{array}{l}r \\
.9\end{array}$ & $\%$ \%. & منخفضVإ. & كفاءة الحل \\
\hline $\begin{array}{l}\varepsilon \\
. \wedge\end{array}$ & $\begin{array}{l}7 \\
1.5\end{array}$ & $\begin{array}{l}r \\
.\end{array}$ & $\% r$. & منخفضVا. & احتمال النجاح \\
\hline $\begin{array}{l}0 \\
\therefore 0\end{array}$ & $\begin{array}{l}\varepsilon \\
. \varepsilon\end{array}$ & $\begin{array}{r}\mu \\
. r\end{array}$ & $\% 1$. & 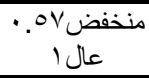 & إمكانية التطبيق \\
\hline $\begin{array}{l}7 \\
. .7\end{array}$ & $\begin{array}{l}0 \\
\therefore 0\end{array}$ & $\begin{array}{l}\varepsilon \\
. \varepsilon\end{array}$ & $\% 1$. & 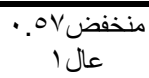 & قدرة العاملين \\
\hline$\varepsilon .9$ & 0.1 & $\overline{r .7}$ & & & الإجمالي \\
\hline
\end{tabular}

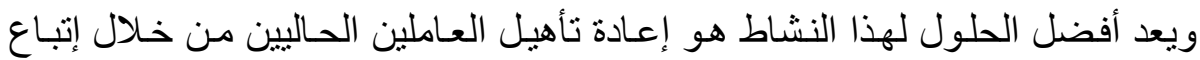
دور ات تدريبية تساعد على زيادة خبر اتهم وكفاءتهم بما يلائم العملية الإنتاجية.

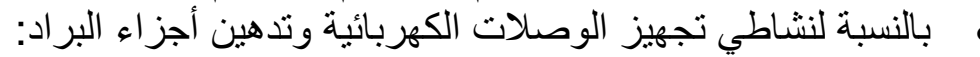

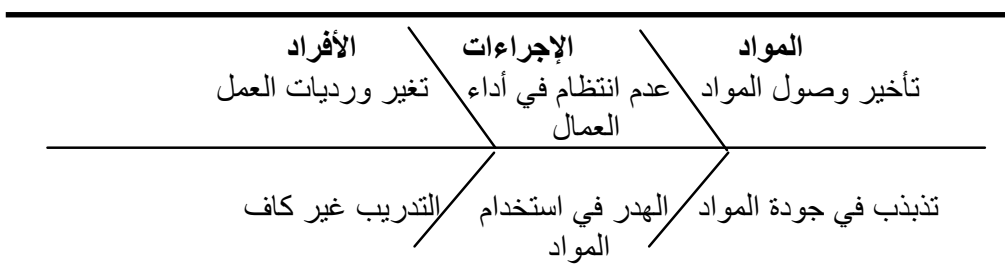

نشاط تجهيز الوصلات الكهربائية

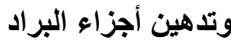

ويعد الهدر في المواد المستخدمة من أكثر الأسباب التي تؤدي إلى ارتفاع التكلفة

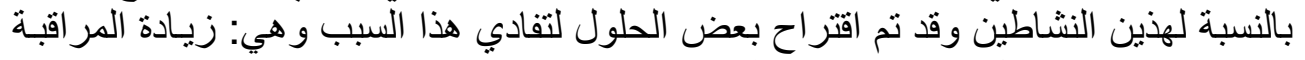
على العاملين - تعديل نمط عملية التسليم للمو اد لـن

\begin{tabular}{|c|c|c|c|c|}
\hline الحل الثاني & الحل الأول & الأهمية النسبية & & المعيار \\
\hline $\begin{array}{c}r \\
. .7\end{array}$ & $\begin{array}{c}r \\
. .9\end{array}$ & $\% \Gamma \cdot$ & منخفضV0V. & تكلفة الحل \\
\hline$\varepsilon$ & $\begin{array}{l}7 \\
1.1\end{array}$ & $\%$ \%. & 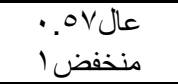 & كفاءة الحل \\
\hline $\begin{array}{r}T \\
.7 \\
\end{array}$ & $\begin{array}{l}0 \\
1 \\
\end{array}$ & $\%$ \%. & $\begin{array}{l}\text { مال منخفا } \\
\end{array}$ & احتمال النجاح \\
\hline $\begin{array}{l}\varepsilon \\
. \varepsilon\end{array}$ & $\begin{array}{l}r \\
. r\end{array}$ & $\% 1$. & منخفض/OV. & إمكانية التطبيق \\
\hline $\begin{array}{l}0 \\
.0 \\
\end{array}$ & $\begin{array}{r}7 \\
. .7 \\
\end{array}$ & $\% 1$. & منخفض/0V. & قدرة العاملين على \\
\hline$r . r$ & $\varepsilon .7$ & & & الإجمالي \\
\hline
\end{tabular}

* المصفوفة من إعداد الباحثث

ويعد تعديل نمط التسليم والاستلام للمو اد أفضل الحلول من أجل تخفيض تكلفة هذين النشاطين.*بالنسبة لنشاط فحص التبريد: 


$$
\text { نشاط فحص البراد }
$$

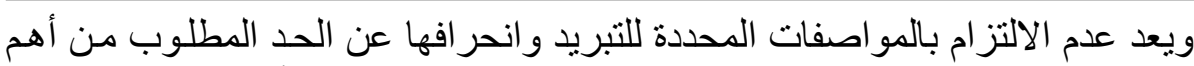

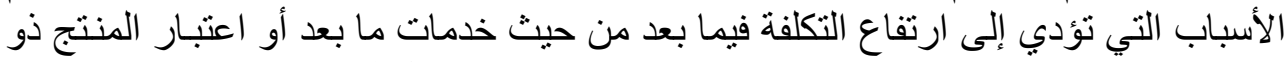

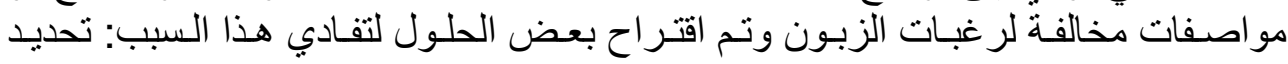

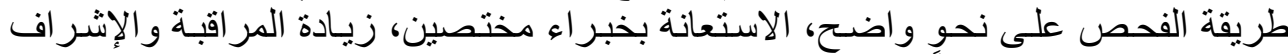

\begin{tabular}{|c|c|c|c|c|c|}
\hline الحل الثالث & الحل الثاني & الحل الأول & الأهمية النسبية & & المعيار \\
\hline $\begin{array}{c}r \\
.9\end{array}$ & $\begin{array}{l}7 \\
1.1\end{array}$ & $\begin{array}{c}r \\
.9\end{array}$ & $\%$ \%. & 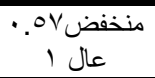 & تكلفة الحل \\
\hline $\begin{array}{l}r \\
. .9\end{array}$ & $\begin{array}{l}\varepsilon \\
1 . r\end{array}$ & $\begin{array}{l}0 \\
1.0\end{array}$ & $\% r$. & منخفضV & كفاءة الحل \\
\hline $\begin{array}{l}5 \\
. .7\end{array}$ & $\begin{array}{l}9 \\
1.5\end{array}$ & $\begin{array}{l}\varepsilon \\
. \wedge\end{array}$ & $\% r$. & منخفضVا. & احتمال النجاح \\
\hline $\begin{array}{l}\varepsilon \\
. \varepsilon\end{array}$ & $\begin{array}{l}0 \\
\therefore 0\end{array}$ & $\begin{array}{l}r \\
. r\end{array}$ & $\% 1$. & 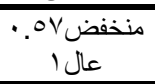 & إمكانية التطبيق \\
\hline $\begin{array}{l}r \\
r . r\end{array}$ & $\begin{array}{l}0 \\
.0\end{array}$ & $\begin{array}{l}\varepsilon \\
. \varepsilon\end{array}$ & $\% 1$. & 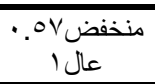 & قدرة العباملين \\
\hline$\Gamma .1$ & $0 . r$ & $r .9$ & & & الإجمالي \\
\hline
\end{tabular}

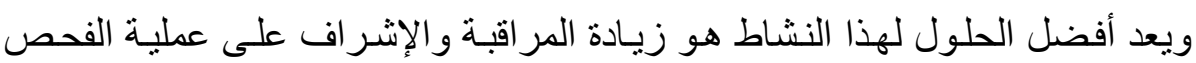

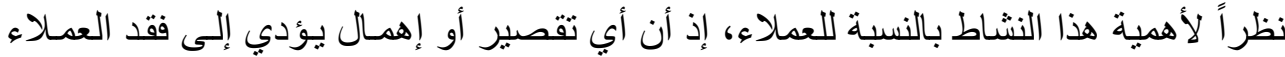

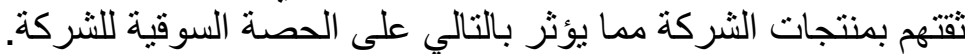

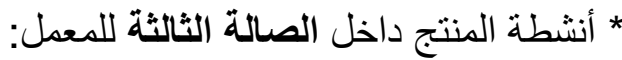

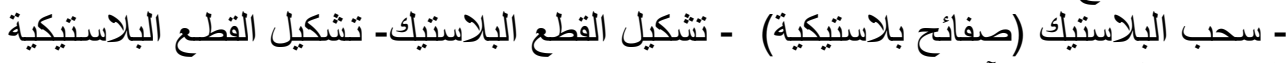

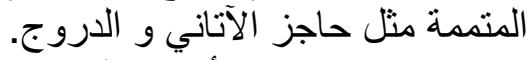
ويمكن تحديد الأسباب المتكررة التي تؤدي إنى إلى ارتفاع التكلفة خلال كل نشاط من الأنشطة السابقة ذلك باستخدام هيكل السمكة:

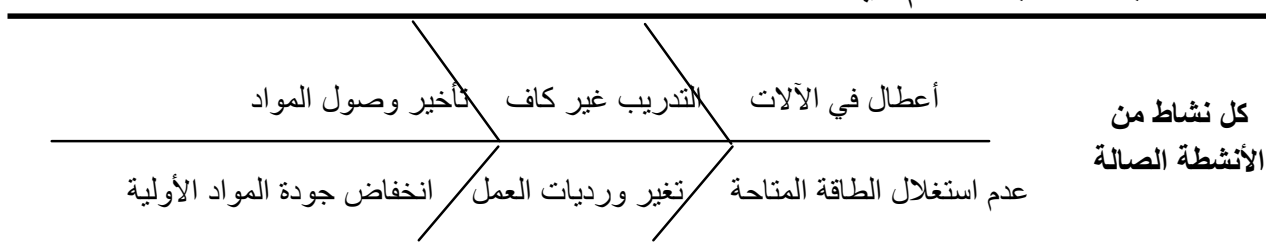

وتعتبر الأعطال المتكررة في الآلات من أكثر الأسباب التي تؤدي إلى ارتفاع التكلفة

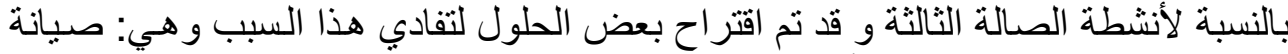

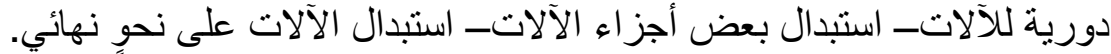
ويتم استخدام مصفوفة الحلول لاختيار الحل الأمثل لهذا النثاط: 


\begin{tabular}{|c|c|c|c|c|c|}
\hline الحل الثالث & الحل الثاني & الحل الأول & الأهمية النسبية & & المعيار \\
\hline $\begin{array}{l}0 \\
1.0\end{array}$ & $\varepsilon$ & $\begin{array}{c}r \\
\cdot .9\end{array}$ & $\% r$. & منخفض/OV. & تكلفة الحل \\
\hline $\begin{array}{l}7 \\
1.1\end{array}$ & $\varepsilon$ & $\varepsilon$ & $\% r$. & 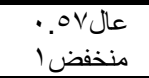 & كفاءة الحل \\
\hline $\begin{array}{l}7 \\
1.5\end{array}$ & $\begin{array}{l}r \\
. .7\end{array}$ & $\begin{array}{l}1 \\
1.4\end{array}$ & $\% r$. & 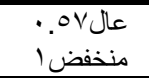 & احتمال النجاح \\
\hline $\begin{array}{l}0 \\
\therefore 0\end{array}$ & $\begin{array}{l}\varepsilon \\
\therefore \varepsilon\end{array}$ & $\begin{array}{l}0 \\
.0\end{array}$ & $\% 1$. & منخفضV0V. & إمكانية التطبيق \\
\hline $\begin{array}{l}7 \\
. .7\end{array}$ & $\begin{array}{l}\varepsilon \\
\therefore \varepsilon\end{array}$ & $\begin{array}{l}7 \\
. .7\end{array}$ & $\% 1$. & منخفض عال & قدرة العاملين على \\
\hline 0.7 & r.A & $\varepsilon . \varepsilon$ & & & الإجمالي \\
\hline
\end{tabular}

* المصفوفة من إعداد الباحث

ويعدّ استبدال بعض أجز اء الآلات من أفضل الحلول لهذه الأنشطة بالنسبة للشركة نظر اً للوضع المالي و التنافسي للشركة.

توزيع تكاليف مرطلة الإنتاج على أنشطة الإنتاج

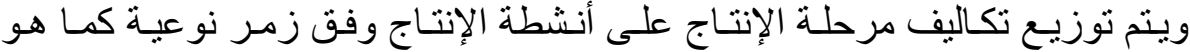

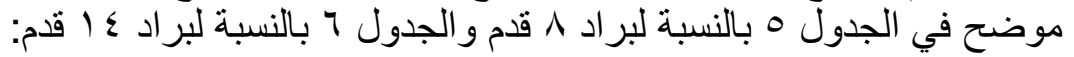

\begin{tabular}{|c|c|c|c|c|c|c|c|c|c|}
\hline \multicolumn{10}{|c|}{ قائمة تكاليف براد ^ م قدم لد } \\
\hline الإجمدي & 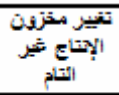 & الإجمالي & 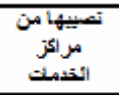 & تحزيلمة & أنذئزمية & أمسئزية & 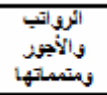 & أمركز & أمركزَ \\
\hline oasivero & $|A| \leqslant, 09$ & $0 \times \ldots r, 14$ & sora,r? & $1+\psi \xi . \cdot Y$ & $110 \times .05$ & poart. 10 & 10.04 .18 & 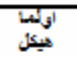 & $0 \leqslant 1$ \\
\hline ririon.og & $1 .+4 \div .19$ & rortolo.:4 & ros19.YA & vi.\&.Y. & $17 .+.14$ & ห.รหน1.20 & Yorh,Ar & |برأس & $0 \leqslant 4$ \\
\hline$\{\Delta q \ldots\{, \eta\}$ & $141 \leqslant 0.2$. & \&Y.AOA,Y & sorar, & $1+4: 5.00$ & $110 \times 0.4$ & portel.o. & $818 \cdot 1.01$ & نكليس & $0 \leqslant . \%$ \\
\hline 1Yrex. & mira.1A & $19 A y \cdot Y .9$ & $9.0 \times .0 \%$ & Mra.1s & rely.Ah & YIAะห, & Traty.r. & كاد & $0 \leqslant . \leqslant$ \\
\hline QY. $\{A . \cdot 3$ & mira.14 & $9+21 A, A\}$ & Q.01.0\% & rina.1: & rely.A & 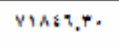 & YOYA,AY & الثهن & ०६.० \\
\hline $1150+1,14$ & 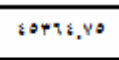 & 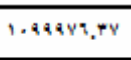 & 11+rel.0. & 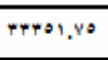 & Fatro. & AQA.YA,YO & $M+O \cdot A Y$ & بيانئي & $0\{\cdot A\}$ \\
\hline$m .1 \leqslant, \% 0$ & $0 \leqslant \leqslant, \pi$ & tos?a,ay & IFOA.YA & 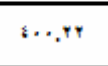 & $r \leqslant Y .07$ & 1. ४४१.,90 & rest.s? & تئنيليل & O OA \\
\hline $11 \times 1.0 .7 \mathrm{~h}$ & para.1A & 1.Aะหน.० & $9.0 \times .0 \%$ & ma.1: & rely.Ah & Y1Aะ१,\% & rrosi.84 & 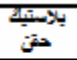 & $0 \leqslant 9$ \\
\hline 1 1 $09 \times 0 . \times Y$ & mira.1A & $18+r 09.18$ & Q.0N.0r & ma.1: & rely.AA & YמAs?. & 0.14.10 & 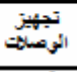 & צוזם \\
\hline १ะ०६०१.० & 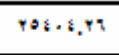 & ir...or,rt & $1+4.9,16$ & 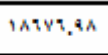 & $17 \times 19.09$ & o.rars.l. & IAAYY.0 & خفتريثي & $0 \leqslant 1 \leqslant$ \\
\hline וr?ave.ir & shaqu,at & 1rloas1.79 & prrag... & m.12,19a & A.A. & aาaरro..० & ग:14.10 & جئيخ خط & risitr \\
\hline \$rl10n.0? & $19+1 .+1$ & s.OPYY,Y & 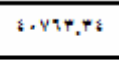 & $1+\ldots 9,14$ & $1.8 \times 9.43$ & $+4+4 \cdot 1 .+0$ & IAAYY.0 & 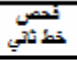 & 0 \\
\hline \&hors:4 & ११४.Q६\% & \$१४.Q:\% & sorar? & $1+46.8$ & 110008 & raqrilo & พหาะถ & & ائب \\
\hline
\end{tabular}




\section{القطيني[r]}

$$
\begin{aligned}
& \text { تكلفة الإنتاج } \\
& \text { فرق تغيير مخزون الإنتاج التام } \\
& \text { مصاريف تسويقية } \\
& \text { تكلفة المبيع } \\
& \text { م إدارية و مالية الإبعة } \\
& \text { التكلفة الإجمالية للإنتاج الكلي } \\
& \text { التكلفة الإجمالية للبر اد الو احد }
\end{aligned}
$$

\begin{tabular}{|c|c|c|c|c|c|c|c|c|c|}
\hline الإجمالي & 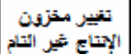 & الإجمأي & تصييها، من مر اكز & |تحوينية جا & أنسئزمية & انمستزية & 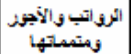 & اسم المركز & رقم ائمركز \\
\hline रूश१६A.०म & 9099.01 & 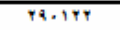 & rrano.0Q & $9+1,{ }^{\circ}$ & $1+1, y^{\circ}$ & 191029,00 & YIITY.T" & أوئما هيكل & $0 \div .1$ \\
\hline $18.17 \% 9.4$ & OY109.8h & 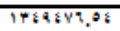 & $1+911 \%, 04$ & myaryo. & AYAYY.O. & 11+10YQ," & $7009,1 \mathrm{~h}$ & أوئما براد & 0?. \\
\hline $74.9+9.19$ & 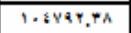 & 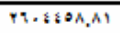 & r\&a0\}1.0Y & $1904+.00$ & 10124.00 & 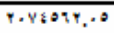 & 1907YY,Y & مكابين & $0 \leqslant . T$ \\
\hline 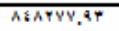 & 18.04 .19 & ATQYYi,YY & $80+41.19$ & 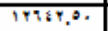 & 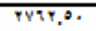 & TYYQस, 1 & सश1700,8 & حدادة و ندام & $0 \%$ \\
\hline 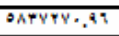 & $F+A 178,0$ & 00281.4 .89 & $07 \times 1+8, A^{*}$ & $101 .+1,40$ & $760+1,90$ & 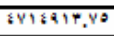 & 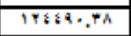 & معب بالاستوتر & $0:-11$ \\
\hline Tha010..1 & piri,rq & Phlsat, Yo & $|A| \leqslant A, \& 4$ & $0.0 v_{0} .$. & $11.0 .$. & $10 . A Y Y, Y S$ & 1.98 .9 .6 & 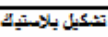 & $0 \leqslant \cdot A_{t}$ \\
\hline OTYYYA,\&9 & 19.04 .17 & $0 \leqslant \$ 4 Y 0,+4$ & $80+1.19$ & 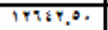 & 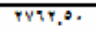 & FYY।Q4,1 & 1.98 .9 .4 & بلاهتيك حقن & $0: .4$ \\
\hline YTPYAY,OO & 19.04 .19 & $p . i v+i, x^{*}$ & $60+1,19$ & 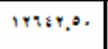 & 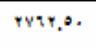 & FYYQR,. & r11vio, & انوتجليزت & זו" \\
\hline$\Gamma T A \Lambda, V A, A T+$ & $1+1+4+44.14$ & $+10: V .7 . Y$ & Fivo9, & Aณ\&QY,० & $18+4 y, 0$ & $\overline{r i k+01, y=}$ & AAR+1,Y. & تبريث غطانتب & $0 \leqslant 15$ \\
\hline $78+1091 \%, 17$ & rovfiv.,14 & $71 \times 8+0.89$ & 917011.01 & $18.9 \times 4.90$ & $4 x+8+, y o$ & $0.2+1.9,10$ & 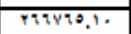 & جمي غطائتي & 0 \\
\hline Y1\{00YY,Y\} & 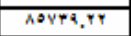 & P.0QYAT,\&2 & 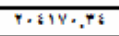 & $071,91,40$ & $1+841,90$ & $199 \times 491,90$ & AलRशI,Y. & 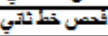 & 0 \\
\hline A1TV., & 12.0 .47 & $v a+10,11$ & $80+14$ & $1 \times 18,70$ & $7 \times 9.70$ & PQYY1Q,PI & $7007 \mathrm{~A} .7 \mathrm{~A}$ & |l| & $0: 1 / 1$ \\
\hline $\mid 49 \times 2009, \%$ & Rorion & 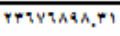 & rinoosa."I & Tritro & $1+A 1 \% 0$ & $1 \times n 02700$ & IYYAST: & & \\
\hline
\end{tabular}

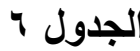

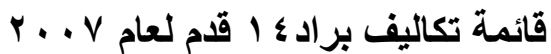

* من أعداد الباحث استتاداً إلى بيانات الثركة.

$$
\begin{aligned}
& \text { تكلفة الإنتاج } \\
& \text { فرق تغيير مخزون الإنتاج التام } \\
& \text { مصاريف تسويقية } \\
& \text { تكلفة المبيع } \\
& \text { م إدارية و مالية } \\
& \text { التكلفة الإجمالية للإنتاج الكلي } \\
& \text { التكلفة الإجمالية للبراد الإنتاج الحدي }
\end{aligned}
$$

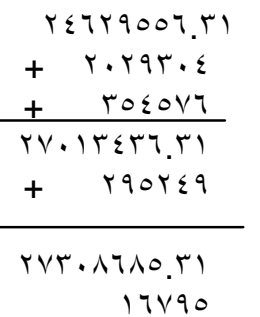

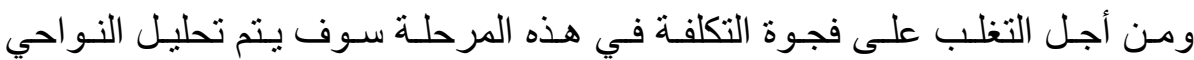

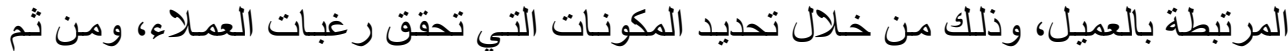
العمل على إلغاء الأنشطة التي تحقق رغبات العملاء و العمل على تخفيض تكلفة الأنشطة

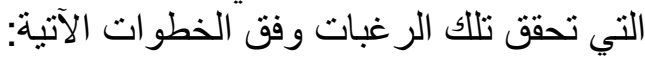

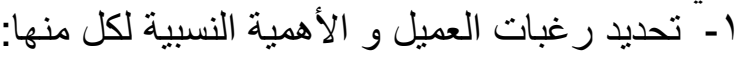

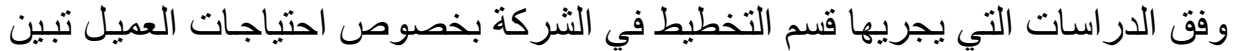

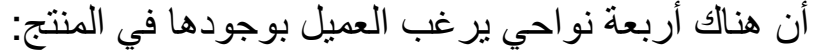

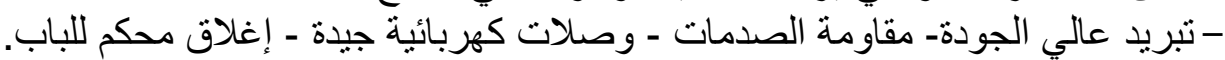

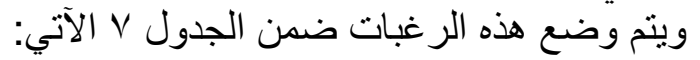




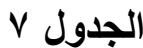

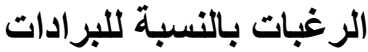

\begin{tabular}{|c|c|c|}
\hline الأهمية النسبية كنسبة مئوية & درجة الأهمية النسبية & 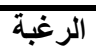 \\
\hline$\%$ \%०.v & 0 & 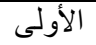 \\
\hline$\% \curlyvee \wedge .0 \vee$ & $\varepsilon$ & الثانية \\
\hline$\%) \leqslant$. १ $^{\circ}$ & r & 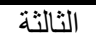 \\
\hline$\% r) . \varepsilon r$ & r & 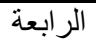 \\
\hline$\% 1 \cdot . .$. & $1 \varepsilon$ & الإجمالي \\
\hline
\end{tabular}

ويتم تحديد تكلفة كل صـالة من صـالات معدل بردى التي فيها إنتاج بر اد م مقدم

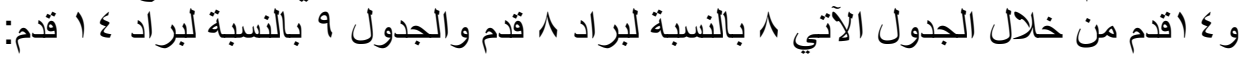

\begin{tabular}{|c|c|c|}
\hline \multicolumn{3}{|c|}{ الجدول 1} \\
\hline نسبة التكاليف & التكلفة الفعلية & الصالة \\
\hline$\% 1 r . Y \leq$ & $r .7 r .01$ & الأولى \\
\hline$\% r \leq .77$ & rVI1.74 & الثانية \\
\hline$\% \circ$ \%. 1 & 0491.01 & الثالثة \\
\hline$\% 1 \ldots .$. & $1.1 V Y . V 0$ & الإجمالي \\
\hline
\end{tabular}
9 الجدول 9

تكلفة أنثطة براد ع ا قام في كل صالة

\begin{tabular}{|c|c|c|}
\hline نسبة التكاليف & التكلفة الفعلية & الصالة \\
\hline$\% r l . r V$ & rosv. $\varepsilon$ & الأولى \\
\hline$\% \pi \cdot .71$ & $0.1 \cdot .0$ & الثانية \\
\hline$\% \leqslant \Lambda . r$ & V979.75 & الثالثة \\
\hline$\% 1 \ldots$ & $17097 . V 4$ & الإجمالي \\
\hline
\end{tabular}

* الجدول من إعداد الباحث .

الصالة الأولىى: صـالة الحدادة و اللحام الصالة الثانيـة: صـالة التجميع الصالة الثالثة:

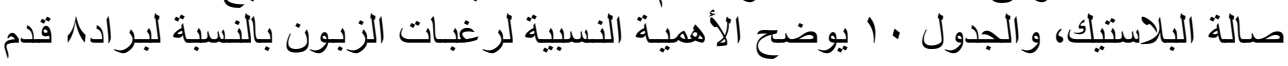

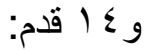

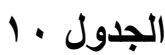

الأهمية النسبية لرغبات العميل بالنسبة لبراد 1 قدم و ع ا قدم

\begin{tabular}{|c|c|c|c|c|c|c|c|c|}
\hline \multicolumn{5}{|c|}{ الأهمية النسبية } & \multirow{2}{*}{ صץ } & \multirow{2}{*}{ صץ } & \multirow{2}{*}{ صا } & \multirow{2}{*}{ رالصبالة } \\
\hline 0 & $\varepsilon$ & $r$ & $r$ & 1 & & & & \\
\hline$x$ & & & & & - & $\because 1$ & - & $1 ر$ \\
\hline & $x$ & & & & $\because 0$ & .1 & $\cdot \varepsilon$ & ru \\
\hline & & & $x$ & & - & $\because 1$ & - & ر \\
\hline & & $x$ & & & $\cdot r$ & $\cdot .7$ & $\because 1$ & $\varepsilon ر$ \\
\hline
\end{tabular}

* تم الحصول على البيانات وفق الدر اسات التي قامت بها الثركة. 


\section{[r|V] القطين}

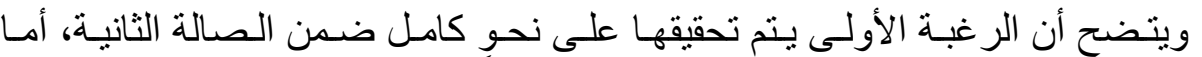

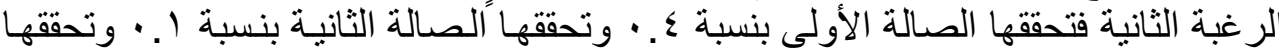

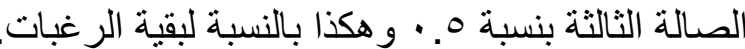

r- إعداد جدول 11 يبين الأهمية النسبية لمكونات المنتج وفق ارتباطها برغبات الزبائن:

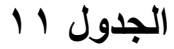

الأهمية النسبية للرغبات وفق مكونات براد ^ قدم و ؛ القدم

\begin{tabular}{|c|c|c|c|c|}
\hline الأهمية النسبية & صن & صץ & ص1 & الصنالة الر غبة \\
\hline$\%$ \% & - & $\%$ Ho.vi & - & 1 \\
\hline$\%$ \% . OV & $\%) \leq . Y \wedge$ & $\%$ \% .А & $\% 11 . \leqslant T$ & ru \\
\hline$\% 1 \leq .49$ & - & $\% 1 \leqslant .49$ & - & ر \\
\hline$\%$ KI. $\leqslant T$ & $\% 7 . \leqslant T$ & $\%$ & $\%$ \%. IE & $\varepsilon$ \\
\hline$\% 1 \cdots \cdot$ & $\% r \cdot . V I$ & $\% 70 . V T$ & $\% 1 \mathrm{H} .0 \mathrm{~V}$ & الأهمبة النسبية للر غبة \\
\hline
\end{tabular}

ه تم الحصول على البيانات وفق الدراسات التي قامت بها الثركة.

ويتم احتساب الأهمية النسبية لكل رغبة وفق الصالة وذللك وفق المعادلة:

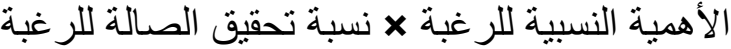

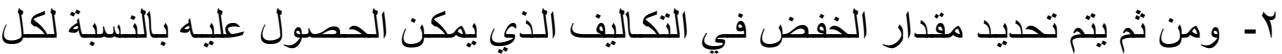

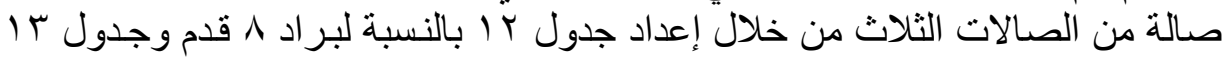
بالنسبة لبر اد ع ا قدم يوضح ذلاص:

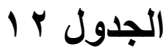

مقدار التخفيض في كل صالة بالنسبة لبراد 1 مثدم

\begin{tabular}{|c|c|c|c|c|}
\hline فجوة التكلفة & التكلفة الفعلية للصالة & التكلفة المستهدفة وفية النسبة & الأهمية النسبية & الصالة \\
\hline Tr.Tr & $\mid r+V . \Lambda 1$ & $1 \Gamma \Lambda \cdot . \varepsilon \varepsilon$ & $\% 1 r .0 \mathrm{~V}$ & صا \\
\hline $71.1 \mathrm{~V}$ & TTY & 7710.04 & $\% 70 . V Y$ & صץr \\
\hline 19.41 & $r \cdot \Lambda V .0$ & YI. T.VA & $\% r \cdot . V I$ & صץ \\
\hline $9 r .11$ & $1 \ldots 19.7 V$ & $1.1 V Y . V 0$ & $\% 1 \ldots .$. & الإجمالي \\
\hline
\end{tabular}

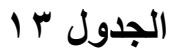

مقدار التخفيض في كل صالة بالنسبة لبراد ؛ ا قدم

\begin{tabular}{|c|c|c|c|c|}
\hline فجوة التكلفة & التكلفة الفعلية للصالة & التكلفة المستهدةفة وفقاً & الأهمية النسبية & الصالة \\
\hline IY.VE & rror.11 & rYrq. Y & $\% 1 r .0 \mathrm{~V}$ & صا \\
\hline $71 . V$ & $1 \cdot 9 \cdot V . r V$ & $1.1 \leq 0.7 V$ & $\% 70 . V T$ & صץ \\
\hline $19 . \leqslant \varepsilon$ & $r \leqslant r v .1 \wedge$ & $T \leqslant \mid V . V \varepsilon$ & $\% r \cdot . V I$ & صץ \\
\hline $9 r . \wedge 1$ & $17097 . \mathrm{VT}$ & $170 \cdot Y .70$ & $\% 1 \ldots$ & الإجمالي \\
\hline
\end{tabular}


r- ومن ثم بتم تحليل أنشطة كل صالة من الصالات الثلاث لتحديد مقدار الخفض في تكلفة

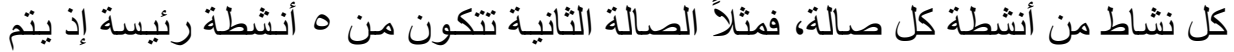

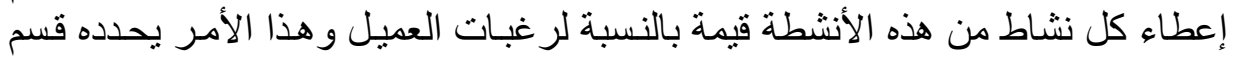

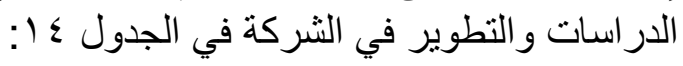

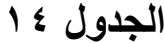

فجوة تكلفة أنشطة الصالة الثانية بالنسبة لبراد ـ ا قاد

\begin{tabular}{|c|c|c|c|c|c|}
\hline فجوة التكلفة & الفعلية & المستتهدفة & الأهمية & & الصالة الثانية \\
\hline $17 . \wedge \mathrm{V}$ & $r Y \cdot T . V V$ & 1119.9 & $\%$ \% द. & 0 & نشاط تجميع قطع المنتج \\
\hline $11 . r$ & TOTr.YT & ro01.9r & $\%$ \%r.o & $\varepsilon$ & نشاط تجهيز الوصلات الكهربائية \\
\hline 11.41 & 1940.10 & $191 \% .9 \leq$ & $\% 1 \vee .70$ & $r$ & نشاط تدهين أجزاء البر اد \\
\hline 11.11 & ITAV.V & IrV0.97 & $\% 11 . \wedge$ & r & نشاط فحص التبريد \\
\hline 11.11 & $19 r 0.10$ & $1911.9 \leq$ & $\% 1 \vee .70$ & $r$ & نشاط تعبئة الغاز \\
\hline $7 . V$ & $1.9 \cdot V . r V$ & $1.1 \leq 0.7 V$ & $\% 1 \ldots$ & IV & 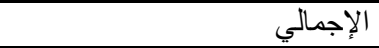 \\
\hline
\end{tabular}

" من اعداد الباحث استناداً إلى بيانات الشركة.

إذ يعتمد الباحث على التحليل الوظيفي لكل نشاط من أنشطة كل صـالة، لكي يتم الته تعديل تكلفة هذا النشاط بما يحقق التكلفة المستهدفة مع الحفاظ على مستوى الجودة المطلوبـة المبـة

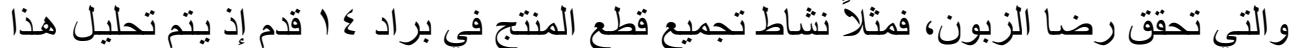

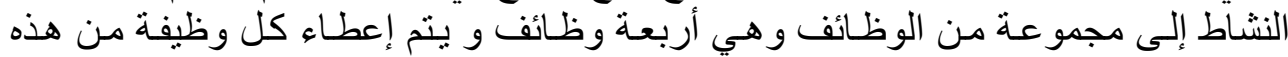
الوظائف أهمية نسبية بالنسبة للعميل ومن ثم يتم تحديد التكلفة المستهدفة لكل وظيفة اعنة كن

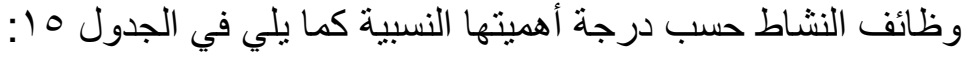

\section{الجدول 10}

التكلفة المستهدفة لكل وظيفة حسب درجة أهميتها النسبية

\begin{tabular}{|c|c|c|}
\hline التكلفة المستهـفة & الأهمبية النسبية & وظائف النشاط \\
\hline $1 Y Y 0.97$ & $\% \leftleftarrows$ & جودة القطع المجمعة \\
\hline $907.9 V$ & $\% r$. & دقة التجميع \\
\hline $7 r V .91$ & $\% r$. & فحص التجميع \\
\hline 511.99 & $\% 1$. & وجود قطع تبديل لها \\
\hline $41 \wedge 9.9$ & $\% 1 \ldots$ & الإجمالي \\
\hline
\end{tabular}

ا. في ظل بيئة التصنيع الحديثة فإنـه نوجد مجالات و اهتمامـات جديدة ذات أهمية كبيرة

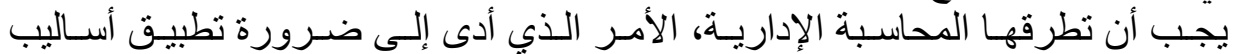
الإدارة الإستر اتيجية. r. اسـتخدام المحاسـبة لأسـاليب الإدارة الإسـتر اتيجية يـؤدي إلـى تـدعيم القـدرة التنافسية للمنشأة. 


\section{[r/9] القطين}

r. اســخدام المحاسـبة لأسـاليب الإدارة الإسـتر اتيجية يـؤدي إلـى زيـادة الحصة السوقية للمنشأة.

ع. العمل على توفير الظروف الملائمة في الثركة محل الدراسـة لتطبيق أسـاليب التصنيع

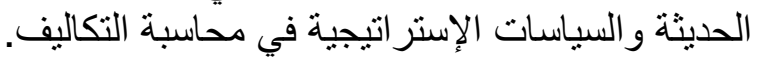

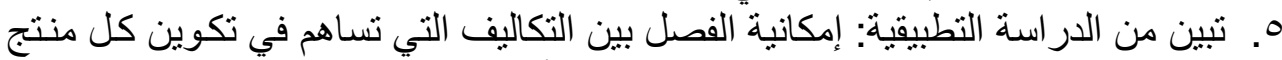

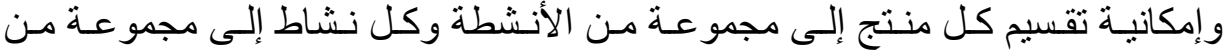

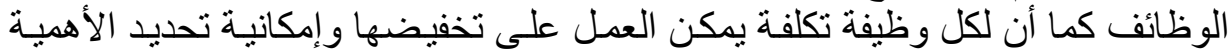
النسبية لرغبات العملاء وتحديد كيفية مساهمة كل نشاط من أنشطة كل منتج في تحقيق رغبات العملاء.

\section{أولاًا - المراجع باللغة العربية}

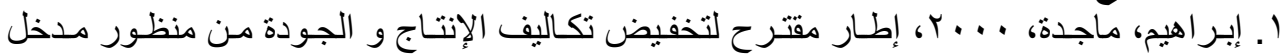

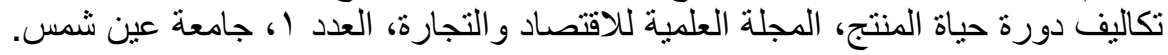

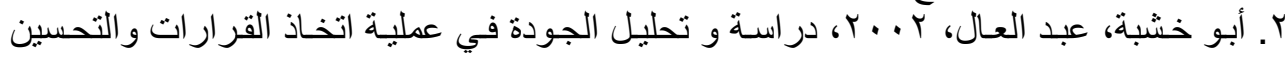

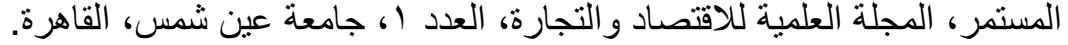

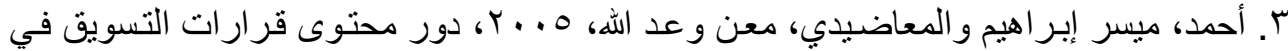

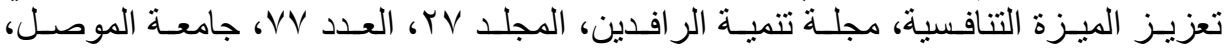

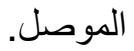

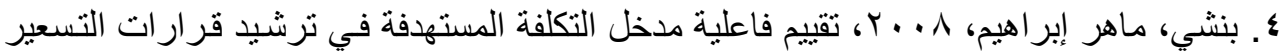

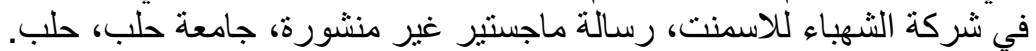

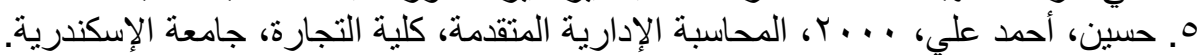

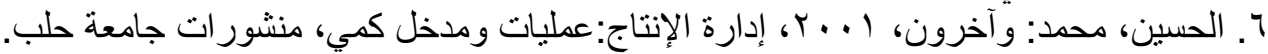

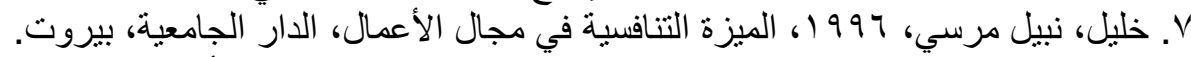

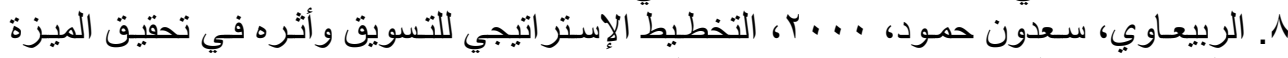

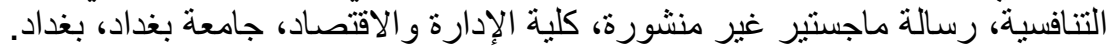

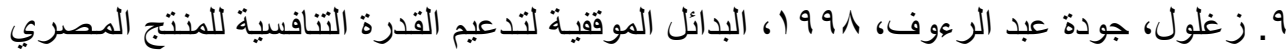

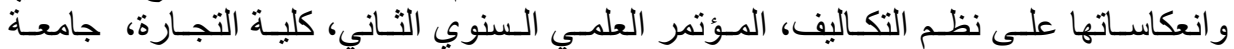
الزقازيق. • 1. السلمي، علي، 1999 1، تطوير أداء و تجديد المنظمات، دار غريب للنشر.

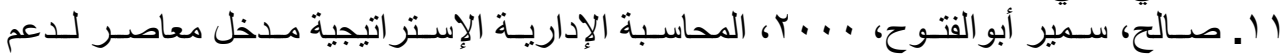

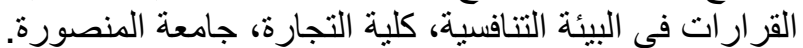

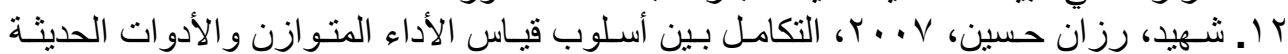

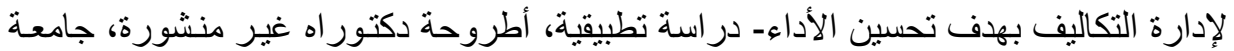
عين شمس، القاهرة.

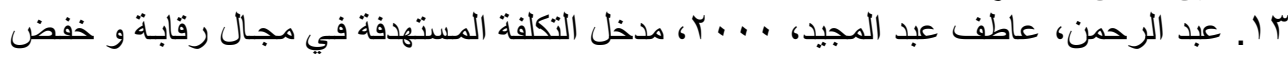
التكلفة كهدف استر اتيجي لتدعيم القدرة التنافسية للشركات المصرية، المجلـة العلميـة لكليـة

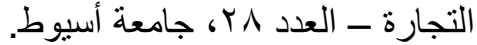
ع ا. عطية، هاثم أحمد، . . . ب، محاسبة التكاليف في المجالات التطبيقية، الدار الجامعية، جامعة ع عين شمس، القاهرة.

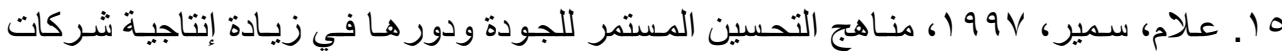

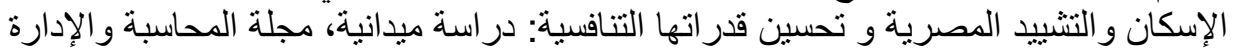
و التأمين، كلية التجارة، جامعة القاهرة. 


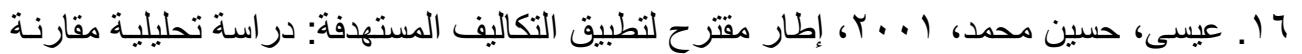

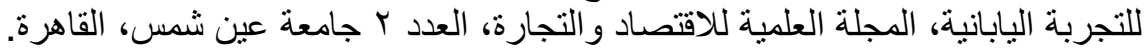

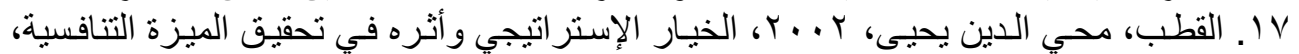

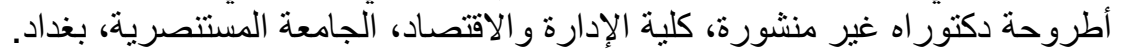

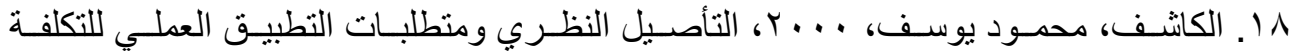

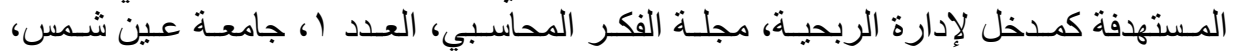

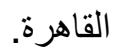

9 1. الكاثف، محمود يوسف، . . .ب، مدخل مقتر ح لتطوير دور المعلومات المحاسبية في إطسار

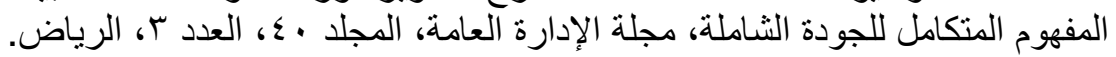

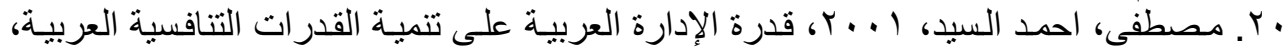

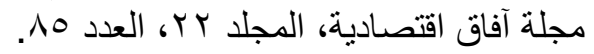

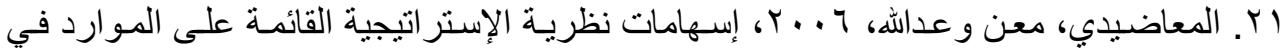

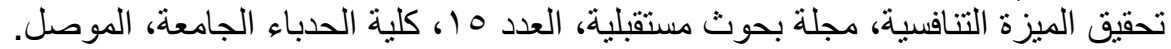

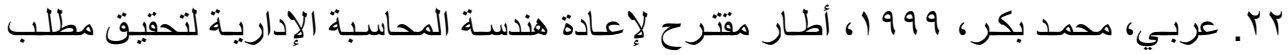

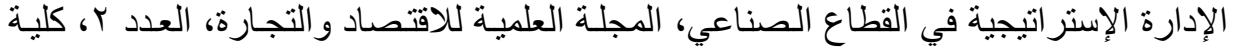

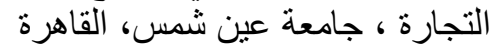

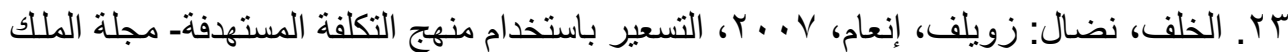

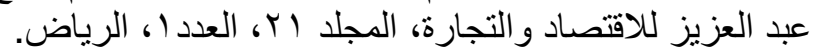

\section{ثانياً- المراجع باللغة الاجنبية}

1. Castellano Joseph F. and Young, Saul, 2003, "Speed Splashier: an team - based target costing exercise ", Journal of Accounting Education, VOL .21, Issue 2.

2. Chandler, A. D, 1992, Strategy and Structure, Cambridge, MA: M.I.T.Press.

3. Davies ,Tony and Boczko, Tony,2005"Business Accounting and Finance", $2^{\text {nd }}$ Edition.

4. Hansen, Don. R, and Mowen, Maryanne, 1997, "Cost Management" Accounting and Control , South -Western College Publishing Thomson Publishing Company, $2^{\text {nd }}$ edition.

5. Hilton, Ronald W, 2005, " Managerial Accounting Creating Value in Dynamic

Business Environment ", $5^{\text {th }}$ ed., New York: McGraw - Hill Companies, Inc.

6. Hoffman N.P, 2000, An Examination of the suitable competitive advantage, Academy of Marketing, science review, N.4.

7. Horngren, Foster ,George and Dater, Srikant.M, 1997, "Cost Management", Managerial Emphasis , Prentice Hall International, Inc, $9^{\text {th }}$ Edition.

8. Kaplan, R. S., 1983, Measuring Manufacturing Performance: a New Challenge to Management Accounting Research, Accounting Review, Vol. 59, No. 3.

9. Kaplan, R. S., 1984, The Evolution Of Management Accounting, The Accounting Review, Vol. 59, No. 3,

10. Kaplan, R. S. ,1988, One Cost System Isn't Enough, Harvard Business Review, Vol. 88, No. 1

11. Kato, Yutaka, 1993, "Target Cost Support System: Lessons from Leading Japanese Companies", Management Accounting research, VOL .4.

12. Ohmae, K., 1982, The Mind of The Strategist NY: McGraw Hill, 13. Pierce, B.,2002,"Target Costing Management: Comprehensive Benchmarking for Competitive Market", Accounting Policies and Procedures, April:

14. Porter, M. E., 1985, Competitive Advantage: Creating and Sustaining Superior Performance NY: Free Press. 


\section{القطيني [rYl}

15. Roslender, R., 1995, Accounting for Strategic Positioning: Responding to the Crisis in Management Accounting, British Journal of Management, Vol. 6, No.1.

16. Roslender R., and S. Hart, 2002, Integrating management accounting and marketing in the pursuit of competitive advantage: The case for strategic management accounting , Critical Perspectives on Accounting, Vol. 13, No. 2.

17. Sakurai, Michiharu, 1989, "Target costing and how to use it", Journal of Cost Management.

18. Simmonds,K.,1981, Strategic Management Accounting, Management Accounting UK, Vol. 59, No. 4.

19. Simmonds, K., 1982, Strategic Management Accounting for Pricing:A Case Example , Accounting and Business Research, Vol. 42.

20. Zabriskie, N. B. and A. B. Huellmantel, 1991, Developing strategic thinking in senior management, Long Range Planning, Vol. 24, No. 6, 